\title{
Novel Insights into the Roles of Rho Kinase in Cancer
}

\author{
Lei Wei $^{1,2} \cdot$ Michelle Surma $^{1} \cdot$ Stephanie Shi $^{1} \cdot$ Nathan Lambert-Cheatham $^{1}$. \\ Jianjian Shi ${ }^{1}$
}

Received: 12 July 2015/Accepted: 24 November 2015/Published online: 2 January 2016

(c) The Author(s) 2016. This article is published with open access at Springerlink.com

\begin{abstract}
Rho-associated coiled-coil kinase (ROCK) is a major downstream effector of the small GTPase RhoA. The ROCK family, consisting of ROCK1 and ROCK2, plays a central role in the organization of the actin cytoskeleton, and is involved in a wide range of fundamental cellular functions such as contraction, adhesion, migration, proliferation, and apoptosis. Since the discovery of effective inhibitors such as fasudil and Y27632, the biological roles of ROCK have been extensively explored in numerous diseases, including cancer. Accumulating evidence supports the concept that ROCK plays important roles in tumor development and progression through regulating many key cellular functions associated with malignancy, including tumorigenicity, tumor growth, metastasis, angiogenesis, tumor cell apoptosis/survival and chemoresistance as well. This review focuses on the new advances of the most recent 5 years from the studies on the roles of ROCK in cancer development and progression; the discussion is mainly focused on the potential value of ROCK inhibitors in cancer therapy.
\end{abstract}

Keywords Rho kinase - Rho kinase pan-inhibitor . ROCK isoform-specific inhibitor · Cancer therapy

Lei Wei

lewei@iu.edu

$凶$ Jianjian Shi

jishi@iu.edu

1 Riley Heart Research Center, Herman B Wells Center for Pediatric Research, Department of Pediatrics, Indiana University, School of Medicine, R4 Building, Room 332, 1044 West Walnut Street, Indianapolis, IN 46202-5225, USA

2 Department of Cellular and Integrative Physiology, Indiana University, School of Medicine, 1044 West Walnut Street, R4-370, Indianapolis, IN 46202-5225, USA

$\begin{array}{ll}\text { Abbreviations } \\ \text { ROCK } & \text { Rho-associated coiled-coil kinase } \\ \text { PKA } & \text { Protein kinase A } \\ \text { PKG } & \text { Protein kinase G } \\ \text { PKC } & \text { Protein kinase C } \\ \text { RBD } & \text { Rho-binding domain } \\ \text { PH } & \text { Pleckstrin homology } \\ \text { MLC } & \text { Myosin light chain } \\ \text { siRNA } & \text { Short interfering RNA } \\ \text { shRNA } & \text { Short hairpin RNA } \\ \text { miRNA } & \text { MicroRNA } \\ \text { EGF } & \text { Epidermal growth factor }\end{array}$

\section{Introduction}

Rho-associated coiled-coil kinase (ROCK) is one of the best characterized effectors of the small GTPase RhoA and belongs to the AGC family of serine/threonine protein kinases, which also includes protein kinases $\mathrm{A}, \mathrm{G}$, and $\mathrm{C}$ (PKA, PKG, PKC) (Ishizaki et al. 1996; Leung et al. 1996; Matsui et al. 1996; Nakagawa et al. 1996). The ROCK family consists of two isoforms, ROCK1 and ROCK2, sharing $65 \%$ overall homology and $92 \%$ homology in the kinase domain. Both kinases contain a catalytic kinase domain at the $\mathrm{N}$ terminus followed by a central coiled-coil domain, which includes the Rho-binding domain (RBD), and a C-terminal pleckstrin-homology $(\mathrm{PH})$ domain. The primary roles of the ROCK family in the organization of actin cytoskeleton have been well established, and they are involved in a wide range of fundamental cellular functions such as contraction, adhesion, migration, proliferation, and apoptosis (Amano et al. 2010a; Julian and Olson 2014; Shi and Wei 2007; Street and Bryan 2011). Since the discovery of the ROCK family, the Rho/ROCK signaling pathway 
has attracted much attention in various research fields, and more than 10,000 articles have been published; in particular, about 2000 articles are focused on Rho/ROCK function in cancer. Accumulating evidence from basic and clinical studies supports the concept that ROCK could be a potential therapeutic target for diverse disorders, including cardiovascular disorders, neurologic disorders, metabolic disorders, and cancers (Huang et al. 2013; Knipe et al. 2015; Morgan-Fisher et al. 2013; Rath and Olson 2012; Sawada and Liao 2014; Shi and Wei 2013; Watzlawick et al. 2014).

The initiation and progression of cancer are multistep events involving cellular transformation, tumor growth, neovascularization, invasion, and metastasis. The roles of ROCK in various cancer processes have been extensively explored with a particular attention focused on tumor cell motility, invasion, and metastasis (Chen et al. 2014; Kale et al. 2015; Mali et al. 2014; Mardilovich et al. 2012; Matsuoka and Yashiro 2014; Morgan-Fisher et al. 2013; Rath and Olson 2012; Schofield and Bernard 2013). In these studies, Y27632 (Uehata et al. 1997) and fasudil (Asano et al. 1987), relatively selective ROCK inhibitors which target the ATP-dependent kinase domain of ROCK1 and ROCK2, have been extensively used in dissecting their roles in cellular signaling and animal disease models. However, these inhibitors inhibit ROCK1 and ROCK2 with similar potency (Breitenlechner et al. 2003; Davies et al. 2000; Ishizaki et al. 2000; Uehata et al. 1997), and cannot be used to distinguish the functional differences between ROCK1 and ROCK2. The specific disruption of each ROCK isoform in mice offers a unique opportunity to analyze in vivo physiological and pathological functions of ROCK1 and ROCK2. This review focuses on the new advances in exploring the roles of ROCK signaling in cancer biology from the past 5 years and the discussion mainly focuses on the potential value of ROCK inhibitors as a novel anti-cancer approach in clinical therapy. Recent findings derived from targeting ROCK1 and ROCK2 by genetic approaches, short interfering RNA (siRNA) or short hairpin RNA (shRNA)-based gene silencing techniques, are also covered in the review.

\section{Overview of ROCK Signaling Pathway}

\section{Substrates of ROCK}

ROCK1 and ROCK2 share more than 30 immediate downstream substrates due to the high degree of homology in their kinase domains, and many of them are related to the regulation of actin cytoskeleton and cell morphology (Amano et al. 2010a; Morgan-Fisher et al. 2013; Schofield and Bernard 2013; Shi and Wei 2007). The canonical substrates of ROCK include myosin light chain (MLC) (Amano et al. 1996; Kureishi et al. 1997), MLC phosphatase (Kawano et al. 1999; Kimura et al. 1996), LIM kinase (Amano et al. 2001; Lin et al. 2003; Maekawa et al. 1999; Ohashi et al. 2000; Sumi et al. 2001), ezrin/radixin/moesin (Matsui et al. 1998), and adducin (Fukata et al. 1999). The consensus amino acid sequences which are phosphorylated on these substrates are $\mathrm{R} / \mathrm{KXS} / \mathrm{T}$ or R/KXXS/T (Kawano et al. 1999; Sumi et al. 2001). However, these substrates can also be phosphorylated by other serine-threonine kinases such as MLC kinase and several other members of the AGC kinase family (Pearce et al. 2010; Prudnikova et al. 2015). The ROCK/MLC phosphatase/MLC and ROCK/LIM kinase/cofilin pathways are profoundly involved in the regulation of actin filament dynamics that are important for the regulation of cell contractility, motility, and morphology. ROCK promotes actomyosin contractility through increasing MLC phosphorylation, and stabilizes actin filaments through LIM kinase activation, resulting in cofilin phosphorylation and thereby inhibiting its actin-depolymerization activity.

Novel ROCK substrates are discovered constantly and added to the list of the large cohort of substrates. A novel substrate is elongation initiation factor-1- $\alpha-1$, which was found using a mutant ROCK2 containing a modified ATP pocket to allow the use of selective ATP analogs, which are not efficiently utilized by other protein kinases (Couzens et al. 2014). Likewise, synthetic peptide substrates have been developed for ROCK2, which can be used in mechanistic studies and drug development (Kang et al. 2011). In the context of tumor cell migration, FilGAP, a GTPase activating protein, is phosphorylated by ROCK in the ameboid migration of carcinoma cells (Saito et al. 2012). Moreover, a recent proteomic approach has identified 121 proteins as candidate substrates (Amano et al. 2010b; Nishioka et al. 2012, 2015). Given the abundance of ROCK substrates which are functionally diverse proteins, ROCK proteins are involved in a wide range of fundamental cellular functions such as contraction, adhesion, migration, proliferation, and apoptosis as discussed below.

\section{Regulation of ROCK Activity}

ROCK exhibits auto-inhibitory activity (Amano et al. 1999); in its inactive form, the C-terminal PH domain and RBD of ROCK interact with the kinase domain, which forms an auto-inhibitory loop. ROCK activation occurs in several ways: through interaction with common activators, via alteration of subcellular localization, and by interaction with isoform-specific regulatory molecules. The small Rho GTPases, including RhoA, RhoB, and RhoC, are the most deliberate ROCK regulators. Activated Rho directly interacts with the RBD of ROCK and induces a conformational 
change initiating interactions of serine/threonine kinases with selective substrates (Blumenstein and Ahmadian 2004; Fujisawa et al. 1996; Ishizaki et al. 1996; Leung et al. 1996; Matsui et al. 1996; Nakagawa et al. 1996). ROCK activity can also be modulated through interaction of C-terminal PH domain with lipid mediators and with the plasma membrane (Feng et al. 1999; Fu et al. 1998; Shirao et al. 2002; Wen et al. 2008), auto-phosphorylation through dimerization (Chuang et al. 2012; Couzens et al. 2009; Doran et al. 2004; Dvorsky et al. 2004; Garg et al. 2008; Jacobs et al. 2006; Yamaguchi et al. 2006), and proteolytic cleavage of the inhibitory C-terminal domain (Coleman et al. 2001; Sebbagh et al. 2001, 2005).

Other than common regulators such as RhoA/RhoB/ RhoC, ROCK1, and ROCK2 can also be individually activated or inhibited by a number of positive or negative regulators. The small GTP-binding protein RhoE interacts with the N-terminal region of ROCK1 (amino acids 1-420) and prevents Rho binding to RBD (Komander et al. 2008; Ongusaha et al. 2006; Riento et al. 2003). Phosphoinositide-dependent protein kinase 1 selectively promotes ROCK1 membrane translocation and blocks its association with RhoE (Pinner and Sahai 2008). ROCK1 is cleaved by caspase-3 at the cleavage site DETD1113 during apoptosis, but this site is not present in ROCK2 (Coleman et al. 2001; Sebbagh et al. 2001). On the other hand, during cytotoxic lymphocyte granule-induced cell death, human ROCK2 can be cleaved by the proapoptotic protease granzyme B at IGLD1131 site; however, the site is not present in ROCK1 (Sebbagh et al. 2005). Human ROCK2, but not ROCK1, can be activated by caspase-2-dependent cleavage in endothelial cells in response to thrombin, though the cleavage site remains to be identified (Sapet et al. 2006). ROCK2 activity can be negatively regulated through interacting with coronin $1 \mathrm{~A} / \mathrm{B}$ via its $\mathrm{PH}$ domain (Rana and Worthylake 2012) and with collapsin response-mediator protein 2 (Yoneda et al. 2012), or positively regulated through interacting with nucleophosmin (Ferretti et al. 2010). Other studies have revealed that ROCK1 and ROCK 2 are phosphorylated by different kinases at multiple sites which could apply various influences on their activities (Du and Hannon 2004; Lee et al. 2010; Lowery et al. 2007).

Many studies are focused on how the Rho/ROCK pathway is associated with cancer progression. Increased Rho/ROCK activity and/or gene expression have been demonstrated in various types of cancers. In addition, increased expression of ROCK protein or mRNA negatively correlates with patient survival and positively with the more advanced tumor stages and worse prognostics, further supporting a contributory role of ROCK in cancer progression (Abe et al. 2008; Gilkes et al. 2014; Lane et al. 2008; Li et al. 2015b; Wong et al. 2009; Zhang et al. 2015).
The factors attributable to the increased Rho/ROCK activity and/or gene expression are context dependent. For example, in responding to the hypoxic microenvironment, hypoxia-inducible factors increase transcription of RhoA and ROCK1 in breast cancer (Gilkes et al. 2014). In some cases, Rho/ROCK activation is part of a downstream signaling cascade: from SMAD4/TGF- $\beta /$ BMP in colorectal cancer (Voorneveld et al. 2014), vascular endothelial growth factor in cervical cancer (He et al. 2010), androgen in prostate cancer (Schmidt et al. 2012), chemokine receptor 7 activation in metastatic squamous cell carcinoma of the head and neck (Xu et al. 2015), epidermal growth factor (EGF)/EGF receptor in pancreatic cancer (Nakashima et al. 2011), and increased expression of the receptor for activated C-kinase-1, a scaffolding protein, interacting with RhoA to activate RhoA/ROCK pathway in breast cancer (Cao et al. 2011). In some cases, Rho/ROCK activation is due to the loss of an antagonist or inhibitor. In hepatocellular carcinoma, the loss of the antagonist RhoE leads to increased ROCK activity (Ma et al. 2013); in invasive lobular carcinoma, p120-cadherin inhibits the antagonist myosin phosphatase Rho-interacting protein leading to increased Rho/ROCK activity (Schackmann et al. 2011); in pancreatic and liver cancer metastasis, the overexpression of tropomyosin-related kinase B leads to binding and sequestering Rho GDP dissociation inhibitor, subsequently activating Rho and its downstream pathways (Li et al. 2009). Different external molecules also induce Rho/ROCK activation. In nasopharyngeal carcinoma, $N, N^{\prime}$ dinitrosopiperazine, a carcinogen, increases phosphorylation of ezrin via Rho/ROCK and PKC pathways, leading to increased motility and invasion (Tang et al. 2011).

Rho/ROCK activity can also be spatially regulated, in particular, during cancer cell migration. In pancreatic ductal adenocarcinoma, RhoA is spatially regulated to the rear and leading edges of cells, leading to cancer cell invasion (Timpson et al. 2011); in brain and breast tumor cells, a RhoA-specific guanine nucleotide exchange factor, Syx, moves to the membrane, where it activates RhoA and downstream effector Dial and suppresses ROCK activity, resulting in polarized cancer cell migration (Dachsel et al. 2013); and NG2, a membrane proteoglycan, promotes amoeboid invasiveness of carcinoma cells through the activation of Rho (Pankova et al. 2012).

\section{Association Between ROCK Polymorphisms and Cancer Development}

To investigate the role of ROCKs in cancer, identifying mutated genes and evaluating their potential risks are important steps. More than 600 somatic coding mutations in both ROCK genes have been identified in human cancer genomes originating from human cancer cell lines and 
primary tumors (http://cancer.sanger.ac.uk/cosmic/ search?q=ROCK1) (http://cancer.sanger.ac.uk/cosmic/ search?q=ROCK2). In addition, several thousands of single nucleotide polymorphisms (SNPs) of ROCK1 and ROCK2 genes have been identified (www.ncbi.nlm.nih. gov/snp/?term=ROCK1) (www.ncbi.nlm.nih.gov/snp/ ?term=ROCK2). The role and impact of these mutations and SNPs in cancer progression remain largely unclear. Recent studies have validated some of the mutations and gene variants, with an emphasis on examining those affecting the coding sequence of ROCK 1 and ROCK2, and determining their impact on cancer pathogenesis (Table 1). Three of the somatic ROCK1 mutations, which were identified in human cancers, have been further analyzed to determine their functional impact by molecular and cellular approaches (Lochhead et al. 2010). Among the three mutations, two lead to premature termination of translation at Tyr405 and Ser1126 in primary breast cancers, and one leads to a substitution of proline 1193 with serine in lung carcinoma. All three mutations increase kinase activity attributable to the removal of auto-inhibition, promote contraction, increase motility, and decrease adhesion (Lochhead et al. 2010). Other mutations, located in the coiled-coil domain, may affect dimerization, RhoA binding, and kinase activation, such as Thr431Asn (Kalender et al. 2010), Asp601Val, and Lys1083Met in ROCK2 (Sari et al. 2013).

Other studies support a potential contributory role of the somatic mutations to human cancers by analyzing the mutation frequency. Two ROCK1 and five ROCK2 polymorphisms were found significantly associating with colorectal cancer development (Sari et al. 2013). ROCK1 is a candidate gene involved in microsatellite instability (genetic instability due to problems with DNA mismatch repair) also correlated with colorectal cancer development (Alhopuro et al. 2012). Thr431Asn polymorphism of the ROCK2 gene could be a risk factor for the metastases of breast cancer (Kalender et al. 2010). ROCK2 was found to be commonly mutated in non-small cell lung cancer by whole-exome sequencing (Liu et al. 2012a), and its copy number and gene expression were increased in malignant peripheral nerve sheath tumors (Upadhyaya et al. 2012).

\section{ROCK and MicroRNAs}

MicroRNAs (miRNA) are small pieces of RNA found between protein coding genes or embedded within their introns. These pre-miRNA transcripts are processed into one or more mature miRNAs of $\sim 21$ to 22 nucleotides which then regulate cell processes by binding to the $3^{\prime}$ untranslated regions (UTR) of targeted messenger RNA, leading to mRNA degradation and decreased translational efficiency. Numerous miRNAs involved in regulating ROCK1 and ROCK2 expression and activity have been identified in cancer tissues. The down-regulation of specific miRNAs is correlated with increased ROCK1 or ROCK2 expression (Table 2). Since the $3^{\prime}$ UTRs of ROCK1 and ROCK2 comprise different sets of miRNA-binding sites, their expressions can be differently regulated by miRNAs. ROCK1 was found to be a target of miR-145 (Wan et al. 2014) and miR-124 (An et al. 2013) in glioma, miR-145 (Li et al. 2014a) and miR-340 (Cai et al. 2014; Zhou et al. 2013) in osteosarcoma, miR-148a (Zheng et al. 2011), miR-135a (Shin et al. 2014) and miR-124 (Hu et al. 2014) in gastric cancer, miR-186 (Cui et al. 2014) and miR-148a ( $\mathrm{Li}$ et al. 2013b) in non-small cell lung cancer cells,

Table 1 ROCK mutations associated with cancers

\begin{tabular}{|c|c|c|c|c|c|}
\hline Isoform & Coding mutation & Domain & Function & Association with cancer & References \\
\hline \multirow[t]{4}{*}{ ROCK1 } & Tyr405* & Kinase & Activation & Breast cancer & $\begin{array}{l}\text { Lochhead et al. } \\
\text { (2010) }\end{array}$ \\
\hline & Ser1126* & PH & Activation & Breast cancer & $\begin{array}{l}\text { Lochhead et al. } \\
\text { (2010) }\end{array}$ \\
\hline & Pro1193S & PH & Activation & Lung cancer & $\begin{array}{l}\text { Lochhead et al. } \\
\text { (2010) }\end{array}$ \\
\hline & Val1309* & PH & May increase kinase activity & $\begin{array}{l}\text { Colorectal cancer with } \\
\text { microsatellite instability }\end{array}$ & $\begin{array}{l}\text { Alhopuro et al. } \\
\text { (2012) }\end{array}$ \\
\hline \multirow[t]{4}{*}{ ROCK2 } & Thr431Asn & $\begin{array}{l}\text { Coiled- } \\
\text { coil }\end{array}$ & $\begin{array}{l}\text { May affect dimerization, Rho binding, and } \\
\text { kinase activation }\end{array}$ & Breast cancer & $\begin{array}{l}\text { Kalender et al. } \\
\text { (2010) }\end{array}$ \\
\hline & Asp601Val & $\begin{array}{l}\text { Coiled- } \\
\text { coil }\end{array}$ & $\begin{array}{l}\text { May affect dimerization, Rho binding, and } \\
\text { kinase activation }\end{array}$ & Colorectal cancer & Sari et al. (2013) \\
\hline & Lys1083Met & $\begin{array}{l}\text { Coiled- } \\
\text { coil }\end{array}$ & $\begin{array}{l}\text { May affect dimerization, Rho binding, and } \\
\text { kinase activation }\end{array}$ & Colorectal cancer & Sari et al. (2013) \\
\hline & $\begin{array}{l}\text { Increased gene copy } \\
\text { number }(2.8 \times)\end{array}$ & & Increased expression/activation & $\begin{array}{l}\text { Malignant peripheral nerve } \\
\text { sheath tumor }\end{array}$ & $\begin{array}{l}\text { Upadhyaya et al. } \\
\text { (2012) }\end{array}$ \\
\hline
\end{tabular}


Table 2 Regulation of ROCK1 and ROCK2 by miRNAs

\begin{tabular}{llll}
\hline Isoform & MiRNA & Cancer & References \\
\hline ROCK1 & miR-124 & Brain & An et al. (2013) \\
& miR-135a & Gastric & Hu et al. (2014) \\
& miR-145 & Bone & Shin et al. (2014) \\
& & Brain & Wan et al. (2014) \\
& miR-146a & Prostrate & Lin et al. (2008) \\
& miR-148a & Gastric & Zheng et al. (2011) \\
& & Lung & Li et al. (2013b) \\
& miR-148b & Breast & Cimino et al. (2013) \\
& miR-186 & Lung & Cui et al. (2014) \\
& miR-340 & Bone & Zhou et al. (2013) \\
& miR-335 & Brain & Lynch et al. (2012) \\
& miR-584 & Renal & Ueno et al. (2011) \\
& miR-1280 & Bladder & Majid et al. (2012) \\
& miR-101 & Liver & Zheng et al. (2015) \\
& miR-124 & Liver & Zheng et al. (2012) \\
mOCK2 & miR-138 & Tongue & Jiang et al. (2010) \\
& miR-139 & Liver & Wong et al. (2011) \\
& miR-200 b/c & Liver & Peng et al. (2013) \\
& miR-135a & Prostate & Kroiss et al. (2015) \\
\hline ROCK1 and 2 & &
\end{tabular}

miR146a (Lin et al. 2008) and miR-135a (Kroiss et al. 2015) in prostate cancer, miR-584 (Ueno et al. 2011) in renal cancer, and miR-1280 (Majid et al. 2012) in bladder cancer. Decreased expression of the miRNAs in cancer tissues leads to increased ROCK expression/activity and increased migration, invasion, or proliferation, which can be rescued by either overexpression of the miRNAs or inhibition of ROCK1 by either a ROCK inhibitor (Y27632) or ROCK1 siRNA molecules (An et al. 2013; Hu et al. 2014; Li et al. 2013b, 2014a; Ueno et al. 2011; Zheng et al. 2011; Zhou et al. 2013). It is worth noting that miRNAs also target other transcripts in addition to ROCK1, such as miR-148b and miR-335 targeting multiple genes in breast cancer (Cimino et al. 2013) and in neuroblastoma cells (Lynch et al. 2012), respectively. Another example is miR135a which targets both ROCK1 and ROCK2 as well as numerous genes involved in cellular movement, cellular assembly/organization, and cell morphology in prostate cancer cells (Kroiss et al. 2015).

In addition to those miRNAs interacting with ROCK1, there are also miRNAs interacting with ROCK2 in cancers, for instance, miR-139 (Wong et al. 2011), miR-124 (Zheng et al. 2012) and miR-101 (Zheng et al. 2015) in hepatocellular carcinoma, miR-200b/c in cholangiocarcinoma (Peng et al. 2013), and miR-138 in oral cancer (Jiang et al. 2010). The down-regulation of these miRNAs in cancer tissues leads to increased ROCK2 levels and increased invasion, migration, and proliferation. These miRNAs also target other transcripts in addition to ROCK2, such as EZH2 with miR-124 (Zheng et al. 2012) and SUZ12 with $\mathrm{miR}-200 \mathrm{~b} / \mathrm{c}$ (Peng et al. 2013). Furthermore, there are miRNAs targeting upstream activators of ROCK, for instance, miR-126 targets the upstream RhoA, and its down-regulation in colorectal cancers with metastasis results in the activation of RhoA/ROCK activity ( $\mathrm{Li}$ et al. 2013c); miR-26a, which is often amplified in glioblastoma, targets the cyclin-dependent kinase-associated phosphatase (KAP, a member of the dual-specificity protein phosphatase family and is able to bind multiple cyclindependent kinases), a novel binding partner and activator of ROCK2; down-regulation of KAP leads to decreased ROCK2 activity and this, in turn, increases Rac GTPasemediated invasion ( $\mathrm{Li}$ et al. 2015a).

While ROCK mRNAs have been shown to be targeted by miRNA-mediated degradation as mentioned above, recent reports also revealed the effects of ROCK signaling on miRNA expression and function. ROCK1 directly interacts with and stabilizes the oncogene c-Myc protein leading to the increased oncomir miR-17-92 cluster expression in breast cancer and prostate cancer (Liu et al. 2009; Zhang et al. 2014). Inhibition of ROCK activity in vascular tumor-forming endothelial cells was reported to alter the global miRNA expression (Stiles et al. 2013). Moreover, ROCK inhibitors enhance miRNA function by promoting miRNA-mediated degradation of mRNA targets; ROCK inhibitors induce a conformational change of ROCK1 thereby enhancing its binding to the transcription factor, hepatocyte nuclear factor 4 alpha, leading to increased transcription of poly(A)-binding protein-interacting protein 2 , which enhances poly(A)-shortening of miRNA-targeted mRNAs and leads to global up-regulation of miRNA function (Yoshikawa et al. 2015). The general reduction in miRNA expression and impaired miRNA processing are commonly observed in human and experimental cancers, suggesting that they may be related to tumorigenesis (Calin and Croce 2006), hence the effects of the ROCK inhibitor-induced increase in global miRNA activity may be valuable for developing novel cancer therapeutics.

\section{ROCK is a Key Player in Cancer Progression}

ROCK and its downstream targets are involved in regulating actin cytoskeleton dynamics, and therefore are responsible for cell migration and motility. In addition, they are implicated in diverse biological processes such as cell junction integrity, cell cycle control, and cell apoptosis. Their roles in various processes of cancer progression, such as tumor invasion/metastasis, proliferation, and 
apoptosis/survival, as well as the roles in both cancer and cancer-associated cells, such as fibroblasts and endothelial cells, have been extensively explored (Chen et al. 2014; Kale et al. 2015; Mali et al. 2014; Matsuoka and Yashiro 2014; Morgan-Fisher et al. 2013; Rath and Olson 2012; Schofield and Bernard 2013). Although ROCK activation is generally considered to be oncogenic, some studies show that ROCK functions as a negative regulator in cancer progression. As a result, the precise role of ROCK in affecting different types of cancer process is context defined, specifically depending on cell type and the microenvironment surrounding a tumor.

\section{ROCK in Tumor Cell Invasion and Metastasis}

The role of the Rho/ROCK pathway in tumor cell invasion and metastasis has been extensively studied since its role in promoting tumor cell dissemination in vivo was firstly reported (Itoh et al. 1999). Most studies favor a positive role of ROCK activation in enhancing tumor cell invasion and metastasis via direct effects on tumor cell motility and/or indirect effects on cancer-associated fibroblasts to increase extracellular matrix stiffness and facilitate cancer cell movement; inhibiting ROCK by chemical inhibitors leads to decreased tumor cell invasion and metastasis. Among the recent studies, Y27632 decreased breast cancer cell invasion/migration in vitro and metastasis in vivo in a mouse model of human breast cancer metastasis to human bone (Liu et al. 2009); fasudil or Y27632 decreased invasion and motility of CaOV3 and SKOV-3 ovarian cancer cell lines (Jeong et al. 2012; Ogata et al. 2009; Peng et al. 2012); fasudil suppressed the proliferation, migration, and invasion of A-549 lung cancer cells (Zhu et al. 2011); Y27632 decreased invasive potential of colon cancer SW620 cells (de Toledo et al. 2012); and Y27632 suppressed progression of hepatocellular carcinoma through both direct effects on the migration and proliferation of hepatocellular carcinoma and indirect effects on the pro-metastatic microenvironment by deactivating activated hepatic stellate cells in fatty liver (Mikuriya et al. 2015). The underlying mechanisms resulting from ROCK inhibition include reduction of stress fiber formation and peripheral focal adhesions (Liu et al. 2009), loss of membrane blebbing and re-established E-cadherin dependent adherent junctions (de Toledo et al. 2012), loss of intracellular cytoskeletal rearrangement (Ogata et al. 2009), inhibition of the epithelial to mesenchymal transition (Castro et al. 2013; de Toledo et al. 2012), and inhibition of proteolytic enzyme expression such as matrix metalloproteinase 9 and urokinase-type plasminogen activator (Jeong et al. 2012).

Contrasting to these studies demonstrating beneficial effects of ROCK inhibition, several others have shown the detrimental effects of ROCK inhibition. Y-27632 treatment activated dormant MCF-7 breast cancer cells through the disintegration of cell junctions coupled with the loss of E-cadherin and $\beta$-catenin from the cell membrane leading to increased migration and invasion in both two-dimensional and three-dimensional substrates (Yang and Kim 2014). Y27632 also increased the invasion of SW620 colon cancer cells in three-dimensional collagen matrix, but not in twodimensional matrix (Vishnubhotla et al. 2012). In addition, treatment with Y-27632 in SW480 colon cancer cells also increased migration associated with dramatically altered focal adhesions (Adachi et al. 2011). Moreover, inhibition of ROCK2 through binding to coronin $1 \mathrm{~A} / \mathrm{B}$ via its $\mathrm{PH}$ domain was required for neuregulin 1 stimulated scattering of MCF7 cells (Rana and Worthylake 2012). Together, these studies reveal that the contribution of Rho/ROCK signaling to cancer cell migration varies depending on the cell line tested and on the surrounding microenvironment.

The contradicting effects of ROCK inhibition on tumor cell invasion and metastasis can be related to the great plasticity of cancer cells in their migratory mechanisms and to the activation of other signaling pathways involved in cell migration, for instance, Rac GTPase-mediated signaling (Fife et al. 2014; Kale et al. 2015; Li et al. 2015a; Matsuoka and Yashiro 2014; Prudnikova et al. 2015; Sadok and Marshall 2014; Yang and Kim 2014). Cancer cells are able to display different modes of motility which has been broadly classified as single-cell and collective-cell migration. Single-cell migration is further subdivided into elongated mesenchymal and rounded amoeboid types which have different requirements of molecular signaling. Cancer cells have also been shown to switch modes of migration after ROCK inhibition, for instance, from rounded amoeboid type to elongated mesenchymal type in Y27632 treated gastric cancer cells (Matsuoka et al. 2011). Drug combinations to simultaneously block several targets may produce greater anti-metastatic effects: combined inhibition of ROCK and Rac reduced mesenchymal motility of Y27632 treated gastric cancer cells (Matsuoka and Yashiro 2014; Matsuoka et al. 2011); combined inhibition of ROCK and myotonic dystrophy kinase-related Cdc42-binding kinases (MRCK) inhibited migration and invasion of lung, breast, melanoma, and pancreatic cancer cells (Kale et al. 2014, 2015). Finally, the recently developed new ROCK inhibitors with higher potency than Y27632 or fasudil may be more effective in blocking tumor cell invasion and metastasis (Sadok et al. 2015).

\section{ROCK in Tumor Cell Proliferation and Angiogenesis}

Similar to its activity in tumor cell invasion and metastasis, a majority of studies support a positive role of ROCK in tumor growth through regulating cell proliferation and 
angiogenesis. Numerous reports indicate that ROCK inhibition decreases tumor cell proliferation and angiogenesis (Chen et al. 2014). Through its well-established role in promoting stress fiber formation, ROCK promotes fibronectin matrix assembly, cell adhesion, and colonization of metastatic kidney tumor cells (Knowles et al. 2015). Y-27632 treatment in melanoma significantly changed 94 gene transcripts, many of which are involved in tumor initiation and progression, indicating that ROCK signaling also contributes to the tumor transcriptome in addition to its well-established role in the regulation of F-actin dynamics (Spencer et al. 2011). In lung cancer, fasudil treatment inhibited the growth of 95D lung carcinoma cells (Yang et al. 2010); it also significantly attenuated angiogenesis as it inhibited lung carcinoma-conditioned endothelial cell proliferation and in vivo invasive ability by causing stress fiber fracture and breakage (Zhang et al. 2012). Moreover, ROCK inhibition may also decrease tumor cell proliferation by preventing the activation of oncogenes. ROCK phosphorylates the oncogene c-Myc at T58 and/or S62, ensuring higher stability and transcriptional activity of c-Myc in breast cancer (Liu et al. 2009) and in prostate cancer (Zhang et al. 2014); hence the inhibition of ROCK lowers c-Myc activity.

ROCK activity plays a critical role in cytokinesis in centrosomes, the microtubule organization centers governing chromosome segregation during cell division. Centrosome abnormality leads to genomic instability, representing a common feature of tumor cells. Extra centrosomes can result in aneuploidy and polyploidy, which are thought to be tumorigenic. At centrosomes, morgana/ chp-1 directly binds ROCK2 and prevents ROCK2 activation by nucleophosmin; the down-regulation of morgana in mice or in patients with atypical chronic myeloid leukemia leads to increased ROCK2 kinase activity, which results in centrosome amplification and cytogenetic abnormalities (Di Savino et al. 2015; Ferretti et al. 2010). In breast cancer cells, BRCA2 directly binds to nucleophosmin and ROCK2 at centrosomes; the dysfunction of BRCA2, which accounts for the majority of heredity breast and ovarian cancer, causes aberrant centrosome amplification and a high frequency of multinucleated cells (Wang et al. 2011). While increased ROCK activity resulted in centrosome abnormality and genomic instability, ROCK inhibitors were also found to further increase chromosome instability and induce massive chromosome segregation errors and suppress $\mathrm{T}$ cell leukemia growth through inducing microtubule-dependent centrosome fragmentation (Oku et al. 2014).

Conversely, ROCK inhibition was also found to increase cell proliferation in other studies. In colon cancer (Nakashima et al. 2010) and pancreatic cancer cells (Nakashima et al. 2011), treatment with Y-27632 induced cell proliferation. These studies suggest that ROCK negatively regulates EGF-induced cell proliferation (Nakashima et al. 2010), while EGF first stimulates the activation of the EGF receptor and subsequently increases cancer cell proliferation, EGF concurrently induces the activation of ROCK, which then turns off the activated EGF receptor pathway via a negative feedback system. Thus, inhibiting ROCK with Y-27632 prevents the negative feedback, leading to increased EGF activity and cell proliferation (Nakashima et al. 2011). Furthermore, ROCK inhibition was reported to promote cell proliferation through the down-regulation of a tumor suppressor gene, phosphatase and tension homolog (PTEN), leading to the up-regulation of Akt phosphorylation which is essential for cell proliferation and survival (Fusella et al. 2014; Yang and Kim 2012). Taken together, ROCK has a general positive role in cancer cell proliferation in many cell types through promoting actomyosin cytoskeleton contractility and cell adhesion, cytokinesis, and activation of oncogenes; though there are some exceptions in specialized contexts through negative feedback on growth factor signaling (for instance, EGF) and promoting tumor suppressor gene activation (for instance, PTEN).

\section{ROCK in Tumor Cell Survival and Apoptosis}

The investigations of the role of ROCK in tumor cell survival and apoptosis returned discordant marks. Many studies have shown that the inhibition of ROCK is beneficial through increasing apoptosis. For example, Y-27632 treatment of cultured melanoma cells decreased tumor cell invasion and altered cell survival; in addition, the treatment reduced melanoma tumor volume in tumor-bearing mice (Routhier et al. 2010). In bladder cancer, fasudil increased the apoptotic response (Abe et al. 2014). In leukemia, ROCK1 bound to Erk1/2, and inhibiting ROCK released Erk1/2, consequently increasing apoptosis (Li et al. 2013a). In acute myeloid leukemia (AML), ROCK1 depletion by genetic knockout or ROCK inhibition with H-1152, Y27632, or fasudil reduced the survival of malignant cells bearing oncogenic form of KIT, FLT3, and BCR-ABL through suppressing MLC phosphorylation (Mali et al. 2011). ROCK1 knockdown by siRNA or fasudil treatment also resulted in increased apoptosis and decreased viability of primary cells isolated from AML patients (Wermke et al. 2015).

Other investigations, in contrast, revealed that the inhibition of ROCK promotes tumor cell survival and chemoresistance, or reduces the apoptotic effects of anticarcinogens. Y-27632 treatment in neuroblastoma increased cell survival and facilitated the development of chemoresistance to cisplatin due in part to altered expression of cisplatin resistance genes (Street et al. 2010). In leukemia, RhoA/ROCK1/PTEN activation was critical to 
apoptosis induced by R-(-)-gossypol acetic acid (AT-101), a natural cottonseed product that exhibits anti-cancer activity, but the treatment with Y27632, or down-regulation of ROCK1 with siRNA lowered the effectiveness of the small molecule inhibitor ( $\mathrm{Li}$ et al. 2014b). Triptolide, an active component of a Chinese herbal remedy, induces apoptosis through caspase-3-mediated ROCK1 activation and MLC phosphorylation (Liu et al. 2013). Curcumininduced apoptosis in ovarian cancer SKOV3 cells in part through activation of RhoA/ROCK pathway (Yin and Sun 2014). Taken together, these studies indicate that ROCK activation is anti-apoptotic in many cell types, especially in leukemia, by intervening oncogenic proliferation and survival signaling, whereas proapoptotic in other specific contexts, in particular in mediating apoptotic signaling triggered by some chemo-drugs or anti-carcinogens.

\section{ROCK in Cancer Stem Cells}

Cancer stem cells, also named tumor-initiating cells, represent a small subpopulation of cancer cells and are recognized as the root cause behind cancer metastasis and recurrence. There has been a great deal of interest in expanding cancer stem cells in vitro for investigating their tumorigenicity. ROCK inhibition was initially observed to facilitate the in vitro growth of human embryonic stem cells by inhibiting dissociation-induced apoptosis, named anoikis, through the blockage of ROCK/MLC-regulated actomyosin contraction (Watanabe et al. 2007). Due to the prominent pro-survival effects of ROCK inhibition, the inclusion of ROCK inhibitors such as Y27632 has become part of standard stem cell culture protocols for embryonic, somatic, and cancer stem cells (Castro et al. 2013; Ohata et al. 2012; Tilson et al. 2015; Watanabe et al. 2007; Zhang et al. 2011). In addition to promoting survival, ROCK inhibitors also increase proliferation of cancer stem cells, for instance, mouse mammary epithelial tumor-initiating cells (Castro et al. 2013), and enhance stem-like phenotypes with increased expression of related stem cell markers (Ohata et al. 2012; Tilson et al. 2015). ROCK inhibition also cooperates with irradiated fibroblast feeder cells to induce conditional reprogramming of normal and tumor epithelial cells from various tissues into adult stem-like cells (Liu et al. 2012b; Palechor-Ceron et al. 2013; Suprynowicz et al. 2012), or into a progenitor cell-like phenotype (Saenz et al. 2014), capable of proliferating indefinitely in vitro. The mechanisms underlying the beneficial effects of ROCK inhibitors in stem cell culture in vitro are attributed to the blockade of actomyosin hypercontraction-mediated apoptosis (Castro et al. 2013; Ohata et al. 2012; Tilson et al. 2015; Watanabe et al. 2007; Zhang et al. 2011), the suppression of NOTCH signaling induced differentiation (Yugawa et al. 2013), and the limitation of epithelial to mesenchymal transition (Castro et al. 2013).
In contrast to the well-documented beneficial effects of ROCK inhibitors in promoting cancer stem cell expansion in culture, fewer studies have investigated the effects of ROCK inhibition on cancer stem cell tumorigenicity in vivo. Increasing ROCK-dependent contractility reduced adhesion of tumor-initiating cells from primary human glioblastoma to soft extracellular matrix leading to a rounded and immotile phenotype with reduced migration and tissue invasion (Wong et al. 2015). In contrast, RhoA/ ROCK activation in stromal cells surrounding cancer stem cells increased stiffness of extracellular matrix leading to increased stem cell adhesion to extracellular matrix and consequently increased spreading, migration, and proliferation (Choi et al. 2015; Wong et al. 2015). Similar to the activation of dormant MCF-7 breast cancer cells by ROCK inhibition as mentioned above (Yang and Kim 2014), ROCK inhibition in cancer stem cells may alter the activation of other signaling pathways involved in regulation of cytoskeleton, for instance, Rac and Cdc42 GTPasemediated signaling activation, therefore increasing cytoskeletal plasticity and cell adhesion to extracellular matrix, and integrin-mediated signaling. These ROCK inhibition-related potential pro-survival and pro-extracellular matrix adhesive effects on cancer stem cells and on dormant cancer cells represent a risk for cancer cell dissemination and metastasis, and therefore need to be considered to avoid the potential undesirable effects of ROCK inhibition therapy.

\section{Overlapping and Differential Roles of ROCK Isoforms in Tumorigenesis}

Current research on ROCK function and its clinical applications as a potential therapeutic target are mainly dependent on the use of small molecule inhibitors; however, these inhibitors modulate the activity of both ROCK proteins. One possible explanation for the apparently inconsistent roles of ROCK in various cancer processes is that the two ROCK isoforms have both overlapping and unique functions, which can even oppose one another in specialized contexts. We have recently shown the distinct roles of the ROCK isoforms in mouse embryonic fibroblasts in regulating the actin cytoskeleton under stress conditions; ROCK1 is involved in MLC phosphorylation, actomyosin contraction, and disruption of central stress fibers, while ROCK2 stabilizes the actin cytoskeleton through cofilin phosphorylation (Shi et al. 2013a, b; Surma et al. 2014; Wei et al. 2015). Other recent studies have also revealed functional differences between ROCK1 and ROCK2 in regulating the actin cytoskeleton and other cellular functions in non-tumor cells (Chun et al. 2012; Herskowitz et al. 2013; Lock et al. 2012; Newell-Litwa et al. 2015). 
In tumor cells, ROCK1 and ROCK2 have recently been reported to have functional differences in regulating adhesion, migration, proliferation, and gene expression, but the underlying mechanisms are not fully understood (Inaba et al. 2010; Mertsch and Thanos 2014; Montalvo et al. 2013; Rochelle et al. 2013; Vega et al. 2011; Vigil et al. 2012; Wang et al. 2014). In non-small cell lung carcinoma, suppression of ROCK1 or ROCK2 expression alone was sufficient to impair anchorage-independent growth (Vigil et al. 2012). A decreased cell migration rate was observed with either ROCK1 or ROCK2 knockdown in mouse pancreatic endothelial cells and angiosarcoma cells, only ROCK2 knockdown showed reduced phosphorylation of MLC phosphatase and cofilin (Montalvo et al. 2013). In retinoblastoma cells, inhibiting ROCK1 with siRNA increased adhesion and decreased invasive capacity similarly to ROCK inhibition by Y27632, but no effect was observed after inhibiting ROCK2 by siRNA, possibly due to a lower expression of ROCK2 than ROCK1 in these cells (Wang et al. 2014). In glioblastoma cells, knocking down ROCK1 by shRNA impaired cell migration and reduced cell proliferation similarly to ROCK inhibition by Y27632, while in contrast, ROCK2 knockdown increased cell migration and proliferation (Mertsch and Thanos 2014). In these cells, ROCK1 knockdown also reduced ROCK2 expression, and not conversely; therefore, ROCK1 knockdown may result in a greater reduction of total ROCK activity than ROCK2 knockdown (Mertsch and Thanos 2014). Together, these studies suggest that inhibition of one ROCK isoform in tumor cells may inhibit tumorigenicity similarly to ROCK pan-inhibition, but with less induction of other signaling pathways involved in cytoskeleton regulation, therefore reducing the potential undesirable effects of ROCK inhibition therapy as reviewed above. The functional differences for ROCK1 and ROCK2 in tumor and non-tumor cells could be explained by their variations in expression levels, subcellular locations, and interaction partners in individual cell types (Amano et al. 2010a; Morgan-Fisher et al. 2013; Schofield and Bernard 2013; Shi and Wei 2007). More investigations on ROCK isoform function in cancer are required in order to elucidate the underlying mechanisms of their functional differences and determine the predominant functional isoform in the relevant tumor types.

\section{Promising Potential of ROCK Inhibition in Cancer Therapy}

The most commonly used chemical inhibitors of ROCK are fasudil (also named HA-1077) (Asano et al. 1987) and Y27632 (Uehata et al. 1997). Fasudil is the only ROCK inhibitor used in humans for systemic applications, and was approved in Japan in 1995 for the prevention and treatment of cerebral vasospasm after surgery in subarachnoid hemorrhagic patients (Shibuya et al. 1992). Hydroxyfasudil is the main metabolite of fasudil after oral administration, and $\mathrm{H}-1152 \mathrm{P}$ is another analog of fasudil, both of them are more potent than fasudil. Because these inhibitors target the ATP-dependent kinase domain of ROCK1 and ROCK2, they are non-isoform specific and also inhibit other serine/ threonine kinases such as PKA and PKC at higher concentrations (Bain et al. 2007; Davies et al. 2000). These inhibitors have shown beneficial effects in a variety of animal disease models including cardiovascular, metabolic, neurodegenerative, and inflammatory diseases, along with various types of cancer (Fukumoto and Shimokawa 2013; Huang et al. 2013; Knipe et al. 2015; Morgan-Fisher et al. 2013; Sawada and Liao 2014; Shi and Wei 2013; Watzlawick et al. 2014). Due to the overall promising results of ROCK inhibition, considerable interest and efforts have been devoted to the development of more potent and selective ROCK inhibitors (Feng and LoGrasso 2014; Guan et al. 2013) including non-isoform selective (Tables 3, 4) and isoform selective inhibitors (Table 5). Among these novel ROCK inhibitors, ripasudil (also named K-115), a close analog of fasudil, has recently reached the stage of clinical application: it was approved in Japan in 2014 for the treatment of glaucoma (GarnockJones 2014).

\section{Development of New ROCK Pan-Inhibitors and Isoform Selective Inhibitors}

The resolution of the crystal structures of ROCK1 complexes with four different ATP-competitive inhibitors (Y27632, fasudil, hydroxyfasudil, and H-1152P) is constructive for developing highly selective and more potent inhibitors (Jacobs et al. 2006). Assisted by structure-guided design, various screening methods have been employed toward the identification of novel inhibitors, including high-throughput library screening (Oh et al. 2013a), structure-guided and fragment-based screening, which uses small molecules to represent fragments rather than entire molecules to find possible molecular interactions ( $\mathrm{Li}$ et al. 2012), and virtual screening using a computer-aided drug design strategy (Gong et al. 2010; Mishra et al. 2014; Shen et al. 2013). Because most of the recently developed novel inhibitors are still targeting the ROCK ATP pocket, they are generally not isoform selective (Tables 3, 4).

Efforts have recently been devoted to the development of ROCK isoform selective inhibitors. Several compounds with significant selectivity for ROCK2 over ROCK1 have been reported (Boerma et al. 2008; Feng et al. 2008; Li et al. 2012) (Table 5). SLx-2119, (also named KD-025), exhibits $\mathrm{IC}_{50}$ values of $0.105 \mu \mathrm{M}$ for ROCK2 and $24 \mu \mathrm{M}$ 
Table 3 Novel ROCK inhibitors and potential therapeutic implications

\begin{tabular}{|c|c|c|c|c|}
\hline Compound & Isoform selectivity & $\begin{array}{l}\text { Therapeutic } \\
\text { Implications }\end{array}$ & Species & References $^{\mathrm{a}}$ \\
\hline \multirow[t]{5}{*}{ SAR-407899 } & \multirow[t]{5}{*}{$\begin{array}{l}\mathrm{IC}_{50} 276 \mathrm{nM} \text { for } \\
\quad \mathrm{ROCK} 1, \mathrm{IC}_{50} 102 \mathrm{nM} \\
\text { for ROCK2 }\end{array}$} & Hypertension & $\begin{array}{l}\text { Rats, } \\
\text { human } \\
\text { tissue }\end{array}$ & Grisk et al. (2012), Lohn et al. (2009) \\
\hline & & \multirow[t]{2}{*}{$\begin{array}{l}\text { Erectile } \\
\quad \text { dysfunction }\end{array}$} & $\begin{array}{l}\text { Rats, } \\
\text { rabbits }\end{array}$ & Guagnini et al. (2012) \\
\hline & & & $\begin{array}{c}\text { Phase } 2 \\
\text { trial }\end{array}$ & NCT00914277 \\
\hline & & \multirow{2}{*}{$\begin{array}{l}\text { Chronic kidney } \\
\text { disease }\end{array}$} & Mice & Babelova et al. (2013) \\
\hline & & & $\begin{array}{l}\text { Phase } 1 \\
\text { trial }\end{array}$ & NCT01485900 \\
\hline \multirow[t]{2}{*}{ Azaindole-1 } & \multirow[t]{3}{*}{$\begin{array}{l}K_{\mathrm{i}} 3.7 \mathrm{nM} \text { for ROCK1, } \\
K_{\mathrm{i}} 4.8 \mathrm{nM} \text { for ROCK2 }\end{array}$} & $\begin{array}{l}\text { Pulmonary } \\
\text { hypertension }\end{array}$ & Rats & Pankey et al. (2012) \\
\hline & & $\begin{array}{l}\text { Erectile } \\
\quad \text { dysfunction }\end{array}$ & Rats & Lasker et al. (2013) \\
\hline FSD-C10 & & Encephalomyelitis & Mice & Li et al. (2014c) \\
\hline DW1865 & $\begin{array}{l}\mathrm{IC}_{50} 100 \mathrm{nM} \text { for } \\
\mathrm{ROCK} 1, \mathrm{IC}_{50} 20 \mathrm{nM} \\
\text { for ROCK2 }\end{array}$ & Hypertension & Rats & Oh et al. (2013b) \\
\hline DL0805 & $\begin{array}{l}\mathrm{IC}_{50} 6.67 \mu \mathrm{M} \text { for } \\
\quad \mathrm{ROCK} 1\end{array}$ & Hypertension & Rats & Gong et al. (2012) \\
\hline \multirow[t]{3}{*}{ AMA 0076} & \multirow{3}{*}{$\begin{array}{l}\mathrm{IC}_{50} 3.7 \mathrm{nM} \text { for ROCK1, } \\
\mathrm{IC}_{50} 2.3 \mathrm{nM} \text { for } \\
\mathrm{ROCK} 2\end{array}$} & \multirow{3}{*}{ Glaucoma } & Rabbits & Van de Velde et al. (2014) \\
\hline & & & $\begin{array}{l}\text { Phase } 1 \\
\text { trial }\end{array}$ & NCT02003547 \\
\hline & & & $\begin{array}{c}\text { Phase } 2 \\
\text { trial }\end{array}$ & NCT02136940 NCT01693315 \\
\hline \multirow[t]{4}{*}{$\begin{array}{l}\text { K-115 } \\
\quad \text { (Ripasudil) }\end{array}$} & \multirow[t]{4}{*}{$\begin{array}{l}\mathrm{IC}_{50} 51 \mathrm{nM} \text { for ROCK1, } \\
\mathrm{IC}_{50} 19 \mathrm{nM} \text { for } \\
\text { ROCK } 2\end{array}$} & \multirow[t]{4}{*}{ Glaucoma } & $\begin{array}{l}\text { Mice, } \\
\text { rabbits, } \\
\text { monkeys }\end{array}$ & Isobe et al. (2014), Yamamoto et al. (2014) \\
\hline & & & $\begin{array}{l}\text { Phase } 1 \\
\text { trial }\end{array}$ & Tanihara et al. (2013a) \\
\hline & & & $\begin{array}{c}\text { Phase } 2 \\
\text { trial }\end{array}$ & Tanihara et al. (2013b) \\
\hline & & & $\begin{array}{c}\text { Approved } \\
\text { (Japan) }\end{array}$ & Garnock-Jones (2014) \\
\hline \multirow[t]{4}{*}{ AR-12286 } & & \multirow[t]{4}{*}{ Glaucoma } & \multirow{2}{*}{$\begin{array}{l}\text { Phase } 1 \\
\text { trial }\end{array}$} & Kopczynski et al. (2013) \\
\hline & & & & NCT01250197 \\
\hline & & & \multirow{2}{*}{$\begin{array}{l}\text { Phase } 2 \\
\text { trial }\end{array}$} & Williams et al. (2011) \\
\hline & & & & $\begin{array}{l}\text { NCT01330979, NCT01060579, NCT01302249, NCT01474135, } \\
\text { NCT01789736, NCT00902200, NCT01699464, NCT02152774, } \\
\text { NCT02173223 }\end{array}$ \\
\hline \multirow[t]{6}{*}{ AR-13324 } & & \multirow[t]{6}{*}{ Glaucoma } & $\begin{array}{l}\text { Rabbits, } \\
\text { monkeys }\end{array}$ & Kiel and Kopczynski (2015), Wang et al. (2015) \\
\hline & & & \multirow{2}{*}{$\begin{array}{c}\text { Phase } 1 \\
\text { trial }\end{array}$} & Levy et al. (2015) \\
\hline & & & & NCT01997879 \\
\hline & & & \multirow{2}{*}{$\begin{array}{c}\text { Phase } 2 \\
\text { trial }\end{array}$} & Bacharach et al. (2015) \\
\hline & & & & NCT02057575, NCT01528787, NCT01731002 \\
\hline & & & $\begin{array}{c}\text { Phase } 3 \\
\text { trial }\end{array}$ & NCT02207621, NCT02246764 \\
\hline
\end{tabular}

Only some most recent studies are included due to space limitation

${ }^{a}$ Clinical trial identifier numbers can be found in https://clinicaltrials.gov 
Table 4 ROCK inhibitors and potential therapeutic implications in cancers

\begin{tabular}{|c|c|c|c|c|}
\hline Compound & Inhibitory activity & Therapeutic implications & Species & References \\
\hline \multirow[t]{6}{*}{ Fasudil } & \multirow[t]{6}{*}{$K_{\mathrm{i}} 0.4 \mu \mathrm{M}$ for $\mathrm{ROCK}$} & Leukemia & Human cells, mice & $\begin{array}{l}\text { Mali et al. (2011), Wermke } \\
\text { et al. (2015) }\end{array}$ \\
\hline & & Brain cancer & Human cells, mice & $\begin{array}{l}\text { Nakabayashi and Shimizu } \\
\text { (2011) }\end{array}$ \\
\hline & & Lung cancer & Human cells & Zhu et al. (2011) \\
\hline & & Ovarian cancer & Human cells, mice & Ogata et al. (2009) \\
\hline & & Liver cancer & Human cells & Takeba et al. (2012) \\
\hline & & Bladder cancer & Human cells & Abe et al. (2014) \\
\hline \multirow[t]{5}{*}{ Y-27632 } & \multirow[t]{5}{*}{$\begin{array}{l}K_{\mathrm{i}} 0.22 \mu \mathrm{M} \text { for ROCK} 1, K_{\mathrm{i}} \\
0.30 \mu \mathrm{M} \text { for ROCK2 }\end{array}$} & Leukemia & Human cells, mice & $\begin{array}{l}\text { Burthem et al. (2007), Mali } \\
\text { et al. (2011) }\end{array}$ \\
\hline & & Breast cancer & Human cells, mice & $\begin{array}{l}\text { Liu et al. (2009), Yang and } \\
\text { Kim (2014) }\end{array}$ \\
\hline & & Melanoma & Human cells, mice & Routhier et al. (2010) \\
\hline & & Prostate cancer & Human cells, mice & Zhang et al. (2014) \\
\hline & & Ovarian cancer & Human cells & Jeong et al. (2012) \\
\hline $\mathrm{H}-1152$ & $K_{\mathrm{i}} 1.6 \mathrm{nM}$ for ROCK & Breast cancer & Human cells, mice & Castro et al. (2013) \\
\hline PT262 & $\mathrm{IC}_{50} 5 \mu \mathrm{M}$ for $\mathrm{ROCK}$ & Lung cancer & Human cells & Tsai et al. (2011) \\
\hline RKI-1447 & $\begin{array}{l}\mathrm{IC}_{50} 14.5 \mathrm{nM} \text { for ROCK1, } \mathrm{IC}_{50} \\
6.2 \mathrm{nM} \text { for ROCK2 }\end{array}$ & Breast cancer & Human cells & Patel et al. (2012) \\
\hline RKI-18 & $\begin{array}{l}\mathrm{IC}_{50} 397 \mathrm{nM} \text { for ROCK1, } \mathrm{IC}_{50} \\
349 \mathrm{nM} \text { for ROCK2 }\end{array}$ & Breast cancer & Human cells & Patel et al. (2014) \\
\hline OXA-06 & $\mathrm{IC}_{50} 5 \mathrm{nM}$ for ROCK & Lung cancer & Human cells & Vigil et al. (2012) \\
\hline DJ4 & $\begin{array}{l}\mathrm{IC}_{50} 5 \mathrm{nM} \text { for ROCK1, } \mathrm{IC}_{50} 50 \mathrm{nM} \\
\quad \text { for ROCK2 }\end{array}$ & $\begin{array}{l}\text { Lung cancer, melanoma, pancreatic } \\
\text { cancer, breast cancer }\end{array}$ & Human cells & Kale et al. (2014) \\
\hline \multirow[t]{2}{*}{ AT13148 } & \multirow{2}{*}{$\begin{array}{l}\mathrm{IC}_{50} 6 \mathrm{nM} \text { for } \mathrm{ROCK} 1, \mathrm{IC}_{50} 4 \mathrm{nM} \\
\quad \text { for } \mathrm{ROCK} 2\end{array}$} & Melanoma & Human cells, mice & Sadok et al. (2015) \\
\hline & & Phase 1 trial & $\begin{array}{l}\text { Breast, prostate, } \\
\text { ovarian cancer }\end{array}$ & NCT01585701 \\
\hline CCT129254 & $\begin{array}{l}\mathrm{IC}_{50} 214 \mathrm{nM} \text { for ROCK1, } \mathrm{IC}_{50} \\
141 \mathrm{nM} \text { for ROCK2 }\end{array}$ & Melanoma & Human Cells, mice & Sadok et al. (2015) \\
\hline
\end{tabular}

Only some most recent studies are included due to space limitation

Table 5 ROCK isoform selective inhibitors and potential therapeutic implications

\begin{tabular}{|c|c|c|c|c|}
\hline Compound & Isoform specificity & $\begin{array}{l}\text { Therapeutic } \\
\text { implications }\end{array}$ & Species & References $^{\mathrm{a}}$ \\
\hline MBPTA (ROCK1) & $\begin{array}{l}\mathrm{IC}_{50} 8.68 \mu \mathrm{M} \text { for ROCK } 1, \mathrm{IC}_{50} 203.2 \mu \mathrm{M} \text { for } \\
\quad \text { ROCK2 }\end{array}$ & Parkinson's disease & Human cells & Chong et al. (2014) \\
\hline \multirow{4}{*}{$\begin{array}{l}\text { KD-025/SLx-2119 } \\
\quad(\text { ROCK2) }\end{array}$} & \multirow{4}{*}{$\begin{array}{l}\mathrm{IC}_{50} 24 \mu \mathrm{M} \text { for ROCK1, } \mathrm{IC}_{50} 0.105 \mu \mathrm{M} \text { for } \\
\quad \mathrm{ROCK} 2\end{array}$} & Cerebral ischemia & Mice & Lee et al. (2014a) \\
\hline & & Rheumatoid arthritis & Human cells & $\begin{array}{l}\text { Zanin-Zhorov et al. } \\
\text { (2014) }\end{array}$ \\
\hline & & \multirow[t]{2}{*}{ Psoriasis vulgaris } & Phase 1 trial & NCT02106195 \\
\hline & & & Phase 2 trial & NCT02317627 \\
\hline Compound 24 (ROCK2) & $\begin{array}{l}\mathrm{IC}_{50} 1.69 \mu \mathrm{M} \text { for ROCK1, } \mathrm{IC}_{50} 0.1 \mu \mathrm{M} \text { for } \\
\text { ROCK } 2\end{array}$ & & Human cells & Li et al. (2012) \\
\hline SR3677 (ROCK2) & $\mathrm{IC}_{50} 56 \mathrm{nM}$ for ROCK1, $\mathrm{IC}_{50} 3 \mathrm{nM}$ for ROCK2 & & $\begin{array}{l}\text { Porcine } \\
\text { tissue }\end{array}$ & Feng et al. (2008) \\
\hline CID5056270 (ROCK2) & $\mathrm{IC}_{50} 13 \mathrm{nM}$ for ROCK $1, \mathrm{IC}_{50} 0.56 \mathrm{nM}$ for ROCK2 & & Human cells & Pireddu et al. (2012) \\
\hline
\end{tabular}

${ }^{a}$ Clinical trial identifier numbers can be found on https://clinicaltrials.gov 
for ROCK1, though it is also an ATP-competitive inhibitor (Boerma et al. 2008). A combined approach using high concentration biochemical assays and fragment-based screening assisted by structure-guided design has discovered a novel series of ROCK inhibitors, in which compound 24 possessed more specificity against ROCK2 $\left(\mathrm{IC}_{50}\right.$ values of $\left.0.1 \mu \mathrm{M}\right)$ over ROCK1 $\left(\mathrm{IC}_{50}\right.$ values of $1.69 \mu \mathrm{M})(\mathrm{Li}$ et al. 2012). SR3677 was also more selective for ROCK2 $\left(\mathrm{IC}_{50}\right.$ values of $\left.\sim 3 \mathrm{nM}\right)$ over ROCK1 $\left(\mathrm{IC}_{50}\right.$ values of $56 \mathrm{nM}$ ) (Feng et al. 2008).

Novel ROCK inhibitors have been used to study noncancer diseases (Tables 3, 5). A benzofuran derivative MBPTA has shown neuroprotective effects in SH-SY5Y neuroblastoma cells (Chong et al. 2014). SAR-407899 improved erectile dysfunction in rats and rabbits (Guagnini et al. 2012) and inhibited renal failure progression in mice with kidney disease (Babelova et al. 2013). Azaindole-1 improved erectile dysfunction (Lasker et al. 2013) and promoted vasodilation in pulmonary hypertensive rats (Pankey et al. 2012). SLx-2119 (KD-025), a highly ROCK2 specific inhibitor, was tested in mice as a treatment for cerebral ischemia (Lee et al. 2014a). FSD-C10 is a fasudil derivative and intranasal deliverable, and it exhibited effects on suppressing experimental autoimmune encephalomyelitis and promoting neuroprotection in mice (Li et al. 2014c). Other studies have reported blood pressure lowering effects of DW1865 in hypertensive rats (Oh et al. 2013b), vasorelaxant effects of DL0805 in isolated rat thoracic aorta (Gong et al. 2012), and intraocular pressure lowering effects of AMA 0076 (Van de Velde et al. 2014) and K115 (Isobe et al. 2014) in rabbits and monkeys as a treatment for glaucoma.

\section{ROCK Inhibitors Broadly Used in Experimental Cancer Studies}

ROCK inhibitors fasudil and Y27632 have been extensively used in studies using cancer cell lines and rodent cancer models, and significant beneficial effects have been shown in many types of cancers (Chen et al. 2014; Kale et al. 2015; Mali et al. 2014; Matsuoka and Yashiro 2014; Morgan-Fisher et al. 2013; Rath and Olson 2012; Schofield and Bernard 2013) (Table 4). Recent experimental studies have further supported fasudil as a drug candidate for hematological malignancies (Mali et al. 2011; Oku et al. 2014; Wermke et al. 2015), lung cancers (Yang et al. 2010, 2012; Zhang et al. 2012; Zhu et al. 2011), bladder cancer (Abe et al. 2014), glioma (Nakabayashi and Shimizu 2011), hepatocellular carcinoma (Takeba et al. 2012), and ovarian cancer (Ogata et al. 2009). Several novel ROCK inhibitors were tested as an anti-cancer therapy (Table 4). PT262 caused cytoskeleton remodeling and was more effective than Y27632 or H-1152 in inhibiting migration of A549 lung carcinoma cells (Tsai et al. 2011). RKI-1447 and RKI18 prevented breast cancer cell migration and invasion, and anchorage-independent colony formation (Patel et al. 2012, 2014). OXA-06 was used to show that anchorage-independent growth and matrigel invasion of non-small cell lung carcinoma cells were ROCK dependent (Vigil et al. 2012). DJ4, a multi-kinase inhibitor of both ROCK and MRCK, inhibited migration and invasion of lung, breast, melanoma, and pancreatic cancer cells (Kale et al. 2014). CCT129254 and AT13148, discovered as ATP-competitive AKT kinase inhibitors, also potently inhibited both ROCK1 and ROCK2 activity leading to a collapsed cytoskeletal phenotype, which was not observed in cells treated with less potent inhibitors Y27632 or H1152 (Sadok et al. 2015). The potent inhibition of actomyosin contraction by CCT129254 and AT13148 dramatically impaired melanoma cell invasion in culture, and reduced metastasis of melanoma cells in vivo (Sadok et al. 2015). As a result of more potent and selective ROCK inhibitors becoming available, more experimental studies and new screening strategy are underway to evaluate their potential use in cancer therapy.

\section{Combinations of ROCK Inhibition with Other Anti- Cancer Therapies}

ROCK inhibition has also been examined as a possible augmentation to current chemotherapy treatments. In chronic myeloid leukemia, Y27632 and fasudil added to the anti-proliferative and pro-apoptotic effects of imatinib, a tyrosine kinase inhibitor (Burthem et al. 2007; Di Savino et al. 2015). In ovarian cancer, fasudil and Y27632 enhanced the anti-cancer drug cisplatin efficacy in inhibiting growth and inducing apoptosis of human cancer cell lines (Ohta et al. 2012). In malignant glioma, ROCK1 knockdown by shRNA increased the efficacy of nimustine hydrochloride, an alkylating drug used for glioma patients in Japan (Inaba et al. 2010). Also in glioma, ROCK2 siRNA worked synergistically with the anti-cancer drug temozolomide, increasing the induction of apoptosis and inhibiting the migration of U251 cells (Wen et al. 2014). In NRAS mutant melanoma, simultaneous inhibition of MEK and ROCK by anti-cancer drug trametinib and fasudil-induced apoptosis and suppressed growth of established tumors, at concentrations where the single drugs had little effect (Vogel et al. 2015). These studies reveal that a combined therapeutic stratagem of ROCK inhibitors with classic or new anti-cancer drugs might provide greater anticancer effects while reducing chemoresistance and side effect.

However, as mentioned above, combining ROCK inhibition with chemotherapeutic agents may lead to enhanced tumor chemoresistance in some circumstances. For 
example, ROCK inhibition by Y27632 in neuroblastoma cells resulted in enhanced tumor survival following cisplatin cytotoxicity (Street et al. 2010). In addition, ROCK inhibition reduced the favorable effects of several natural anti-carcinogens: indole-3-carbinol in inhibiting motility in breast cancer cells (Brew et al. 2009); curcumin in inducing apoptosis in ovarian cancer cells (Yin and Sun 2014); R-(-)-gossypol acetic acid (Li et al. 2014b); and triptolide (Liu et al. 2013) in inducing apoptosis in leukemia cells. Hence these detrimental effects of ROCK inhibitors need to be considered and should be ruled out while developing novel anti-cancer therapies incorporating ROCK inhibitors.

\section{Clinical Implications of ROCK Inhibitors for Cancers and Non-Cancer Diseases}

Despite the significant promise achieved from experimental studies of merging ROCK inhibition into therapeutic strategies, there is only one reported clinical trial using ROCK inhibitors in cancer treatment: AT13148 in phase 1 clinical trial initiated in 2012 for the treatment of advanced solid tumors (ClinicalTrials.gov identifier NCT01585701). AT13148 also inhibits several members of AGC kinase family including AKT and PKA (Sadok et al. 2015). Of the four most used ROCK inhibitors (Y-27632, fasudil, hydroxyfasudil, and H-1152P), fasudil is the only one approved for the treatment of vasospasm after subarachnoid hemorrhage (Shibuya et al. 1992), and has been used in clinical studies primarily for the treatment of cardiovascular diseases (Shi and Wei 2013). Current clinical trials for fasudil found on ClinicalTrials.gov include atherosclerosis (NCT00120718, NCT00670202), Reynaud's phenomenon (NCT00498615), diabetes complications (NCT01823081), and neuronal disease (NCT01935518). Clinical trials using novel ROCK inhibitors have mainly been conducted for cardiovascular disease and eye disease (Tables 3, 5). SAR-407899 has been used to treat kidney disease (NCT01485900) and erectile dysfunction (NCT00914277). SLx-2119 (KD-025) has been used to treat psoriasis vulgaris (NCT02106195) and examines the response in autoimmune disease (ZaninZhorov et al. 2014). Several clinical studies have been performed to treat glaucoma, ocular hypertension, and eye disease including AMA0076 in phase 1 (NCT02003547) and phase 2 trials (NCT01693315, NCT02136940), AR12286 in phase 1 (Kopczynski et al. 2013) (NCT01250197) and phase 2 trials (Williams et al. 2011) (NCT01330979, NCT01060579, NCT01302249, NCT01474135, NCT017 89736, NCT00902200, NCT01699464, NCT02152774, NCT02173223), AR-13324 in phase I (Levy et al. 2015) (NCT01997879) and phase 2 trials (Bacharach et al. 2015) (NCT02057575, NCT01528787, NCT01731002). After phase 3 clinical trials, Ripasudil (K-115) was approved for glaucoma in Japan in 2014 (Garnock-Jones 2014). Given the accumulated indexes of safety and efficiency from fasudil and some novel ROCK isoform-specific inhibitors in clinic trials, the application prospect of anti-cancer drugs targeting ROCK is exhilarating; we expect ROCK inhibitors will become valuable anti-cancer members in the near future and will make contributions to reducing tumor growth, decreasing metastasis, and improving disease outcome.

\section{Conclusions and Future Direction}

The ROCK proteins contribute to a broad range of cellular functions with their main impact on the regulation of many cytoskeletal-associated proteins. Accumulating evidences have been showing that ROCK signaling is critically responsible, at least in part, for many important cancerassociated phenotypes. There is an increasing interest in targeting ROCK signaling in cancer therapeutics, especially in obstructing tumor cell invasion, metastasis, tumor growth, angiogenesis, cancer-associated alterations of extracellular matrix, and hematological malignancies. Although the ROCK inhibitor fasudil has been available in clinical application for 20 years, it has not yet been used in cancer treatment, and the number of clinical trials for human cancer is still limited.

There are a number of challenges in translating updating knowledge of ROCK signaling into anti-cancer therapy; the current information on the role of ROCK signaling in tumorigenicity is still incomplete, in particular, the mechanisms underlying both the positive and negative roles of ROCK in regulating migration, proliferation, apoptosis/survival, and chemoresistance of tumor cells, including primary tumor cells, tumor stem cells, and dormant tumor cells, remain unclarified. Nevertheless, it has become progressively clear that the consequences of ROCK inhibition and the induction of compensatory signaling pathways, especially those involving in cytoskeleton regulation, largely depend on the tumor cell type, cell context, and the microenvironment; therefore, the complexity in evaluating the application of ROCK inhibitors is augmented. Combined inhibition of ROCK and compensatory signaling could be useful to avoid potential undesirable effects of ROCK inhibition. Furthermore, the first generation of ROCK inhibitors including fasudil shows nonspecific inhibitory effects on other kinases, so it may cause off-target effects. Many more potent and selective ROCK inhibitors have recently been developed, some of them may show promising potential in cancer therapy in the near future. It is worth noting that the combination therapy of 
ROCK inhibitors and other anti-cancer drugs produces greater anti-cancer effects while resistance to single agent is reduced.

There is increased agreement that ROCK1 and ROCK2 have both redundant and non-redundant functions, and isoform-specific inhibition may therefore elicit different biological effects. Although the majority of currently available ROCK inhibitors are suitable initial tools for investigating the role of ROCK in cancer, their limitation in mechanistic studies is unavoidable due to their nonisoform selective nature. Additionally, ROCK1 and ROCK2 expression and/or activity can be separately regulated by numerous factors, which either positively or negatively modify their catalytic activity and/or subcellular localization. Moreover, there are an increased number of somatic mutations and miRNAs being discovered and evaluated for their differing impacts on ROCK isoform expression and activity. Hence, in order to develop isoform-specific targeting strategy for cancer therapy, it is necessary to understand the different functions of each ROCK isoform in cancer pathophysiology and ascertain the major functional isoform in specific tumor types; consequently, it will reduce toxic and undesirable effects than pan-inhibition in clinic application. Recently developed ROCK1 and ROCK2 isoform-specific genetically modified mouse models have offered a unique opportunity to analyze in vivo physiological and pathological functions of ROCK1 and ROCK2 (Lee et al. 2014b; Rikitake et al. 2005; Shi et al. 2011; Shimizu et al. 2005, 2013; Soliman et al. 2015; Thumkeo et al. 2003; Zhang et al. 2006), including cancer development and progression (Mali et al. 2011; Samuel et al. 2011). Some novel isoform selective inhibitors are becoming commercially available and will serve as valuable tools for further dissecting the roles of ROCK1 and ROCK2 in cancer and other diseases. Importantly, the continuation of significant progress in basic and preclinical researches will undoubtedly move ROCK isoform inhibitors to future clinical practice.

Acknowledgments This work was supported by the National Institutes of Health grants (HL107537), a Grant-in-Aid award from American Heart Association, Midwest Affiliate (12GRNT12060525), and by the Riley Children's Foundation.

\section{Compliance with ethical standards}

Conflict of interest The authors declare no conflict of interest.

Open Access This article is distributed under the terms of the Creative Commons Attribution 4.0 International License (http:// creativecommons.org/licenses/by/4.0/), which permits unrestricted use, distribution, and reproduction in any medium, provided you give appropriate credit to the original author(s) and the source, provide a link to the Creative Commons license, and indicate if changes were made.

\section{References}

Abe H, Kamai T, Tsujii T et al (2008) Possible role of the RhoC/ ROCK pathway in progression of clear cell renal cell carcinoma. Biomed Res 29:155-161

Abe H, Kamai T, Hayashi K et al (2014) The Rho-kinase inhibitor HA-1077 suppresses proliferation/migration and induces apoptosis of urothelial cancer cells. BMC Cancer 14:412

Adachi S, Yasuda I, Nakashima M et al (2011) Rho-kinase inhibitor upregulates migration by altering focal adhesion formation via the Akt pathway in colon cancer cells. Eur J Pharmacol 650:145-150

Alhopuro P, Sammalkorpi H, Niittymaki I et al (2012) Candidate driver genes in microsatellite-unstable colorectal cancer. Int $\mathbf{J}$ Cancer 130:1558-1566

Amano M, Ito M, Kimura K et al (1996) Phosphorylation and activation of myosin by Rho-associated kinase (Rho-kinase). J Biol Chem 271:20246-20249

Amano M, Chihara K, Nakamura N et al (1999) The COOH terminus of Rho-kinase negatively regulates Rho-kinase activity. J Biol Chem 274:32418-32424

Amano T, Tanabe K, Eto T et al (2001) LIM-kinase 2 induces formation of stress fibres, focal adhesions and membrane blebs, dependent on its activation by Rho-associated kinase-catalysed phosphorylation at threonine-505. Biochem J 354(Pt 1):149-159

Amano M, Nakayama M, Kaibuchi K (2010a) Rho-kinase/ROCK: a key regulator of the cytoskeleton and cell polarity. Cytoskeleton 67:545-554

Amano M, Tsumura Y, Taki K et al (2010b) A proteomic approach for comprehensively screening substrates of protein kinases such as Rho-kinase. PLoS One 5:e8704

An L, Liu Y, Wu A et al (2013) microRNA-124 inhibits migration and invasion by down-regulating ROCK1 in glioma. PLoS One 8:e69478

Asano T, Ikegaki I, Satoh S et al (1987) Mechanism of action of a novel antivasospasm drug, HA1077. J Pharmacol Exp Ther 241:1033-1040

Babelova A, Jansen F, Sander K et al (2013) Activation of Rac-1 and RhoA contributes to podocyte injury in chronic kidney disease. PLoS One 8:e80328

Bacharach J, Dubiner HB, Levy B et al (2015) Double-masked, randomized, dose-response study of AR-13324 versus latanoprost in patients with elevated intraocular pressure. Ophthalmology 122:302-307

Bain J, Plater L, Elliott M et al (2007) The selectivity of protein kinase inhibitors: a further update. Biochem J 408:297-315

Blumenstein L, Ahmadian MR (2004) Models of the cooperative mechanism for Rho effector recognition: implications for RhoAmediated effector activation. J Biol Chem 279:53419-53426

Boerma M, Fu Q, Wang J et al (2008) Comparative gene expression profiling in three primary human cell lines after treatment with a novel inhibitor of Rho kinase or atorvastatin. Blood Coagul Fibrinolysis 19:709-718

Breitenlechner C, Gassel M, Hidaka H et al (2003) Protein kinase A in complex with Rho-kinase inhibitors Y-27632, Fasudil, and H-1152P: structural basis of selectivity. Structure 11:1595-1607

Brew CT, Aronchik I, Kosco K et al (2009) Indole-3-carbinol inhibits MDA-MB-231 breast cancer cell motility and induces stress fibers and focal adhesion formation by activation of Rho kinase activity. Int J Cancer 124:2294-2302

Burthem J, Rees-Unwin K, Mottram R et al (2007) The rho-kinase inhibitors Y-27632 and fasudil act synergistically with imatinib to inhibit the expansion of ex vivo CD34(+) CML progenitor cells. Leukemia 21:1708-1714 
Cai H, Lin L, Tang M et al (2014) Combined microRNA-340 and ROCK1 mRNA profiling predicts tumor progression and prognosis in pediatric osteosarcoma. Int J Mol Sci 15:560-573

Calin GA, Croce CM (2006) MicroRNA signatures in human cancers. Nat Rev Cancer 6:857-866

Cao XX, Xu JD, Xu JW et al (2011) RACK1 promotes breast carcinoma migration/metastasis via activation of the RhoA/Rho kinase pathway. Breast Cancer Res Treat 126:555-563

Castro DJ, Maurer J, Hebbard L et al (2013) ROCK1 inhibition promotes the self-renewal of a novel mouse mammary cancer stem cell. Stem Cells 31:12-22

Chen W, Mao K, Liu Z et al (2014) The role of the RhoA/Rho kinase pathway in angiogenesis and its potential value in prostate cancer (review). Oncol Lett 8:1907-1911

Choi DS, Stark DJ, Raphael RM et al (2015) SDF-1alpha stiffens myeloma bone marrow mesenchymal stromal cells through the activation of RhoA-ROCK-Myosin II. Int J Cancer 136:E219E229

Chong CM, Shen M, Zhou ZY et al (2014) Discovery of a benzofuran derivative (MBPTA) as a novel ROCK inhibitor in protecting against MPP-induced oxidative stress and cell death in SHSY5Y cells. Free Radic Biol Med 74:283-293

Chuang HH, Yang CH, Tsay YG et al (2012) ROCKII Ser1366 phosphorylation reflects the activation status. Biochem $\mathrm{J}$ 443:145-151

Chun KH, Araki K, Jee Y et al (2012) Regulation of glucose transport by ROCK1 differs from that of ROCK2 and is controlled by actin polymerization. Endocrinology 153:1649-1662

Cimino D, De Pitta C, Orso F et al (2013) miR148b is a major coordinator of breast cancer progression in a relapse-associated microRNA signature by targeting ITGA5, ROCK1, PIK3CA, NRAS, and CSF1. FASEB J 27:1223-1235

Coleman ML, Sahai EA, Yeo M et al (2001) Membrane blebbing during apoptosis results from caspase-mediated activation of ROCK I. Nat Cell Biol 3:339-345

Couzens AL, Saridakis V, Scheid MP (2009) The hydrophobic motif of ROCK2 requires association with the $\mathrm{N}$-terminal extension for kinase activity. Biochem J 419:141-148

Couzens AL, Gill RM, Scheid MP (2014) Characterization of a modified ROCK2 protein that allows use of N6-ATP analogs for the identification of novel substrates. BMC Biotechnol 14:2

Cui G, Cui M, Li Y et al (2014) MiR-186 targets ROCK1 to suppress the growth and metastasis of NSCLC cells. Tumour Biol 35:8933-8937

Dachsel JC, Ngok SP, Lewis-Tuffin LJ et al (2013) The Rho guanine nucleotide exchange factor Syx regulates the balance of dia and ROCK activities to promote polarized-cancer-cell migration. Mol Cell Biol 33:4909-4918

Davies SP, Reddy H, Caivano M et al (2000) Specificity and mechanism of action of some commonly used protein kinase inhibitors. Biochem J 351(Pt 1):95-105

de Toledo M, Anguille C, Roger L et al (2012) Cooperative antiinvasive effect of Cdc42/Rac1 activation and ROCK inhibition in SW620 colorectal cancer cells with elevated blebbing activity. PLoS One 7:e48344

Di Savino A, Panuzzo C, Rocca S et al (2015) Morgana acts as an oncosuppressor in chronic myeloid leukemia. Blood $125: 2245-2253$

Doran JD, Liu X, Taslimi P et al (2004) New insights into the structure-function relationships of Rho-associated kinase: a thermodynamic and hydrodynamic study of the dimer-tomonomer transition and its kinetic implications. Biochem $\mathrm{J}$ 384(Pt 2):255-262

Du J, Hannon GJ (2004) Suppression of p160ROCK bypasses cell cycle arrest after Aurora-A/STK15 depletion. Proc Natl Acad Sci USA 101:8975-8980
Dvorsky R, Blumenstein L, Vetter IR et al (2004) Structural insights into the interaction of ROCKI with the switch regions of RhoA. J Biol Chem 279:7098-7104

Feng Y, LoGrasso PV (2014) Rho kinase inhibitors: a patent review (2012-2013). Expert Opin Ther Pat 24:295-307

Feng J, Ito M, Kureishi Y et al (1999) Rho-associated kinase of chicken gizzard smooth muscle. J Biol Chem 274:3744-3752

Feng Y, Yin Y, Weiser A et al (2008) Discovery of substituted 4-(pyrazol-4-yl)-phenylbenzodioxane-2-carboxamides as potent and highly selective Rho kinase (ROCK-II) inhibitors. J Med Chem 51:6642-6645

Ferretti R, Palumbo V, Di Savino A et al (2010) Morgana/chp-1, a ROCK inhibitor involved in centrosome duplication and tumorigenesis. Dev Cell 18:486-495

Fife CM, McCarroll JA, Kavallaris M (2014) Movers and shakers: cell cytoskeleton in cancer metastasis. $\mathrm{Br} \mathrm{J}$ Pharmacol 171:5507-5523

Fu X, Gong MC, Jia T et al (1998) The effects of the Rho-kinase inhibitor Y-27632 on arachidonic acid-, GTPgammaS-, and phorbol ester-induced $\mathrm{Ca}^{2+}$-sensitization of smooth muscle. FEBS Lett 440:183-187

Fujisawa K, Fujita A, Ishizaki T et al (1996) Identification of the Rhobinding domain of p160ROCK, a Rho-associated coiled-coil containing protein kinase. J Biol Chem 271:23022-23028

Fukata Y, Oshiro N, Kinoshita N et al (1999) Phosphorylation of adducin by Rho-kinase plays a crucial role in cell motility. J Cell Biol 145:347-361

Fukumoto Y, Shimokawa H (2013) Rho-kinase inhibitors. Handb Exp Pharmacol 218:351-363

Fusella F, Ferretti R, Recupero D et al (2014) Morgana acts as a proto-oncogene through inhibition of a ROCK-PTEN pathway. J Pathol 234:152-163

Garg R, Riento K, Keep N et al (2008) N-terminus-mediated dimerization of ROCK-I is required for RhoE binding and actin reorganization. Biochem J 411:407-414

Garnock-Jones KP (2014) Ripasudil: first global approval. Drugs 74:2211-2215

Gilkes DM, Xiang L, Lee SJ et al (2014) Hypoxia-inducible factors mediate coordinated RhoA-ROCK1 expression and signaling in breast cancer cells. Proc Natl Acad Sci USA 111:E384E393

Gong LL, Fang LH, Peng JH et al (2010) Integration of virtual screening with high-throughput screening for the identification of novel Rho-kinase I inhibitors. J Biotechnol 145:295-303

Gong L, Peng J, Fang L et al (2012) The vasorelaxant mechanisms of a Rho kinase inhibitor DL0805 in rat thoracic aorta. Molecules 17:5935-5944

Grisk O, Schluter T, Reimer N et al (2012) The Rho kinase inhibitor SAR407899 potently inhibits endothelin-1-induced constriction of renal resistance arteries. J Hypertens 30:980-989

Guagnini F, Ferazzini M, Grasso M et al (2012) Erectile properties of the Rho-kinase inhibitor SAR407899 in diabetic animals and human isolated corpora cavernosa. J Transl Med 10:59

Guan R, Xu X, Chen M et al (2013) Advances in the studies of roles of Rho/Rho-kinase in diseases and the development of its inhibitors. Eur J Med Chem 70:613-622

He M, Cheng Y, Li W et al (2010) Vascular endothelial growth factor C promotes cervical cancer metastasis via up-regulation and activation of RhoA/ROCK-2/moesin cascade. BMC Cancer 10:170

Herskowitz JH, Feng Y, Mattheyses AL et al (2013) Pharmacologic inhibition of ROCK2 suppresses amyloid-beta production in an Alzheimer's disease mouse model. J Neurosci 33:19086-19098

$\mathrm{Hu} \mathrm{CB}, \mathrm{Li} \mathrm{QL}, \mathrm{Hu}$ JF et al (2014) miR-124 inhibits growth and invasion of gastric cancer by targeting ROCK1. Asian Pac J Cancer Prev 15:6543-6546 
Huang H, Lee DH, Zabolotny JM et al (2013) Metabolic actions of Rho-kinase in periphery and brain. Trends Endocrinol Metab 24:506-514

Inaba N, Ishizawa S, Kimura M et al (2010) Effect of inhibition of the ROCK isoform on RT2 malignant glioma cells. Anticancer Res 30:3509-3514

Ishizaki T, Maekawa M, Fujisawa K et al (1996) The small GTPbinding protein Rho binds to and activates a $160 \mathrm{kDa}$ Ser/Thr protein kinase homologous to myotonic dystrophy kinase. EMBO J 15:1885-1893

Ishizaki T, Uehata M, Tamechika I et al (2000) Pharmacological properties of Y-27632, a specific inhibitor of rho-associated kinases. Mol Pharmacol 57:976-983

Isobe T, Mizuno K, Kaneko Y et al (2014) Effects of K-115, a rhokinase inhibitor, on aqueous humor dynamics in rabbits. Curr Eye Res 39:813-822

Itoh K, Yoshioka K, Akedo H et al (1999) An essential part for Rhoassociated kinase in the transcellular invasion of tumor cells. Nat Med 5:221-225

Jacobs M, Hayakawa K, Swenson L et al (2006) The structure of dimeric ROCK I reveals the mechanism for ligand selectivity. J Biol Chem 281:260-268

Jeong KJ, Park SY, Cho KH et al (2012) The Rho/ROCK pathway for lysophosphatidic acid-induced proteolytic enzyme expression and ovarian cancer cell invasion. Oncogene 31:4279-4289

Jiang L, Liu X, Kolokythas A et al (2010) Downregulation of the Rho GTPase signaling pathway is involved in the microRNA-138mediated inhibition of cell migration and invasion in tongue squamous cell carcinoma. Int J Cancer 127:505-512

Julian L, Olson MF (2014) Rho-associated coiled-coil containing kinases (ROCK): structure, regulation, and functions. Small GTPases 5:e29846

Kale VP, Hengst JA, Desai DH et al (2014) A novel selective multikinase inhibitor of ROCK and MRCK effectively blocks cancer cell migration and invasion. Cancer Lett 354:299-310

Kale VP, Hengst JA, Desai DH et al (2015) The regulatory roles of ROCK and MRCK kinases in the plasticity of cancer cell migration. Cancer Lett 361:185-196

Kalender ME, Demiryurek S, Oztuzcu S et al (2010) Association between the Thr431Asn polymorphism of the ROCK2 gene and risk of developing metastases of breast cancer. Oncol Res 18:583-591

Kang JH, Asai D, Tsuchiya A et al (2011) Peptide substrates for Rhoassociated kinase 2 (Rho-kinase 2/ROCK2). PLoS One 6:e22699

Kawano Y, Fukata Y, Oshiro N et al (1999) Phosphorylation of myosin-binding subunit (MBS) of myosin phosphatase by Rhokinase in vivo. J Cell Biol 147:1023-1038

Kiel JW, Kopczynski CC (2015) Effect of AR-13324 on episcleral venous pressure in Dutch belted rabbits. J Ocul Pharmacol Ther 31:146-151

Kimura K, Ito M, Amano M et al (1996) Regulation of myosin phosphatase by Rho and Rho-associated kinase (Rho-kinase). Science 273:245-248

Knipe RS, Tager AM, Liao JK (2015) The Rho kinases: critical mediators of multiple profibrotic processes and rational targets for new therapies for pulmonary fibrosis. Pharmacol Rev 67:103-117

Knowles LM, Gurski LA, Maranchie JK et al (2015) Fibronectin matrix formation is a prerequisite for colonization of kidney tumor cells in fibrin. J Cancer 6:98-104

Komander D, Garg R, Wan PT et al (2008) Mechanism of multi-site phosphorylation from a ROCK-I:RhoE complex structure. EMBO J 27:3175-3185

Kopczynski C, Novack GD, Swearingen D et al (2013) Ocular hypotensive efficacy, safety and systemic absorption of AR12286 ophthalmic solution in normal volunteers. Br J Ophthalmol 97:567-572
Kroiss A, Vincent S, Decaussin-Petrucci M et al (2015) Androgenregulated microRNA-135a decreases prostate cancer cell migration and invasion through downregulating ROCK1 and ROCK2. Oncogene 34:2846-2855

Kureishi Y, Kobayashi S, Amano M et al (1997) Rho-associated kinase directly induces smooth muscle contraction through myosin light chain phosphorylation. J Biol Chem 272:12257-12260

Lane J, Martin TA, Watkins G et al (2008) The expression and prognostic value of ROCK I and ROCK II and their role in human breast cancer. Int J Oncol 33:585-593

Lasker GF, Pankey EA, Allain AV et al (2013) The selective Rhokinase inhibitor azaindole-1 has long-lasting erectile activity in the rat. Urology 81:465 e467-465 e414

Lee HH, Tien SC, Jou TS et al (2010) Src-dependent phosphorylation of ROCK participates in regulation of focal adhesion dynamics. J Cell Sci 123(Pt 19):3368-3377

Lee JH, Zheng Y, von Bornstadt D et al (2014a) Selective ROCK2 Inhibition in focal cerebral ischemia. Ann Clin Transl Neurol $1: 2-14$

Lee SH, Huang H, Choi K et al (2014b) ROCK1 isoform-specific deletion reveals a role for diet-induced insulin resistance. Am J Physiol Endocrinol Metab 306:E332-E343

Leung T, Chen XQ, Manser E et al (1996) The p160 RhoA-binding kinase ROK alpha is a member of a kinase family and is involved in the reorganization of the cytoskeleton. Mol Cell Biol 16:5313-5327

Levy B, Ramirez N, Novack GD et al (2015) Ocular hypotensive safety and systemic absorption of AR-13324 ophthalmic solution in normal volunteers. Am J Ophthalmol 159(980-985):e981

Li Z, Chang Z, Chiao LJ et al (2009) TrkBT1 induces liver metastasis of pancreatic cancer cells by sequestering Rho GDP dissociation inhibitor and promoting RhoA activation. Cancer Res 69:7851-7859

Li R, Martin MP, Liu Y et al (2012) Fragment-based and structureguided discovery and optimization of Rho kinase inhibitors. J Med Chem 55:2474-2478

Li F, Jiang Q, Shi KJ et al (2013a) RhoA modulates functional and physical interaction between ROCK1 and Erk1/2 in seleniteinduced apoptosis of leukaemia cells. Cell Death Dis 4:e708

Li J, Song Y, Wang Y et al (2013b) MicroRNA-148a suppresses epithelial-to-mesenchymal transition by targeting ROCK1 in non-small cell lung cancer cells. Mol Cell Biochem 380:277-282

Li N, Tang A, Huang S et al (2013c) MiR-126 suppresses colon cancer cell proliferation and invasion via inhibiting RhoA/ ROCK signaling pathway. Mol Cell Biochem 380:107-119

Li E, Zhang J, Yuan T et al (2014a) miR-145 inhibits osteosarcoma cells proliferation and invasion by targeting ROCK1. Tumour Biol 35:7645-7650

Li G, Liu L, Shan C et al (2014b) RhoA/ROCK/PTEN signaling is involved in AT-101-mediated apoptosis in human leukemia cells in vitro and in vivo. Cell Death Dis 5:e998

Li YH, Yu JZ, Liu CY et al (2014c) Intranasal delivery of FSD-C10, a novel Rho kinase inhibitor, exhibits therapeutic potential in experimental autoimmune encephalomyelitis. Immunology 143:219-229

Li H, Jiang X, Yu Y et al (2015a) KAP regulates ROCK2 and Cdk2 in an RNA-activated glioblastoma invasion pathway. Oncogene 34:1432-1441

Li J, Bharadwaj SS, Guzman G et al (2015b) ROCK I has more accurate prognostic value than MET in predicting patient survival in colorectal cancer. Anticancer Res 35:3267-3273

Lin T, Zeng L, Liu Y et al (2003) Rho-ROCK-LIMK-cofilin pathway regulates shear stress activation of sterol regulatory element binding proteins. Circ Res 92:1296-1304

Lin SL, Chiang A, Chang D et al (2008) Loss of mir-146a function in hormone-refractory prostate cancer. RNA 14:417-424 
Liu S, Goldstein RH, Scepansky EM et al (2009) Inhibition of rhoassociated kinase signaling prevents breast cancer metastasis to human bone. Cancer Res 69:8742-8751

Liu P, Morrison C, Wang L et al (2012a) Identification of somatic mutations in non-small cell lung carcinomas using whole-exome sequencing. Carcinogenesis 33:1270-1276

Liu X, Ory V, Chapman S et al (2012b) ROCK inhibitor and feeder cells induce the conditional reprogramming of epithelial cells. Am J Pathol 180:599-607

Liu L, Li G, Li Q et al (2013) Triptolide induces apoptosis in human leukemia cells through caspase-3-mediated ROCK1 activation and MLC phosphorylation. Cell Death Dis 4:e941

Lochhead PA, Wickman G, Mezna M et al (2010) Activating ROCK1 somatic mutations in human cancer. Oncogene 29:2591-2598

Lock FE, Ryan KR, Poulter NS et al (2012) Differential regulation of adhesion complex turnover by ROCK1 and ROCK2. PLoS One 7:e31423

Lohn M, Plettenburg O, Ivashchenko Y et al (2009) Pharmacological characterization of SAR407899, a novel rho-kinase inhibitor. Hypertension 54:676-683

Lowery DM, Clauser KR, Hjerrild M et al (2007) Proteomic screen defines the Polo-box domain interactome and identifies Rock2 as a Plk1 substrate. EMBO J 26:2262-2273

Lynch J, Fay J, Meehan M et al (2012) MiRNA-335 suppresses neuroblastoma cell invasiveness by direct targeting of multiple genes from the non-canonical TGF-beta signalling pathway. Carcinogenesis 33:976-985

Ma W, Wong CC, Tung EK et al (2013) RhoE is frequently downregulated in hepatocellular carcinoma (HCC) and suppresses HCC invasion through antagonizing the Rho/Rho-kinase/myosin phosphatase target pathway. Hepatology 57:152-161

Maekawa M, Ishizaki T, Boku S et al (1999) Signaling from Rho to the actin cytoskeleton through protein kinases ROCK and LIMkinase. Science 285:895-898

Majid S, Dar AA, Saini S et al (2012) MicroRNA-1280 inhibits invasion and metastasis by targeting ROCK1 in bladder cancer. PLoS One 7:e46743

Mali RS, Ramdas B, Ma P et al (2011) Rho kinase regulates the survival and transformation of cells bearing oncogenic forms of KIT, FLT3, and BCR-ABL. Cancer Cell 20:357-369

Mali RS, Kapur S, Kapur R (2014) Role of Rho kinases in abnormal and normal hematopoiesis. Curr Opin Hematol 21:271-275

Mardilovich K, Olson MF, Baugh M (2012) Targeting Rho GTPase signaling for cancer therapy. Future Oncol 8:165-177

Matsui T, Amano M, Yamamoto T et al (1996) Rho-associated kinase, a novel serine/threonine kinase, as a putative target for small GTP binding protein Rho. EMBO J 15:2208-2216

Matsui T, Maeda M, Doi Y et al (1998) Rho-kinase phosphorylates $\mathrm{COOH}$-terminal threonines of ezrin/radixin/moesin (ERM) proteins and regulates their head-to-tail association. J Cell Biol 140:647-657

Matsuoka T, Yashiro M (2014) Rho/ROCK signaling in motility and metastasis of gastric cancer. World J Gastroenterol 20:1375613766

Matsuoka T, Yashiro M, Kato Y et al (2011) RhoA/ROCK signaling mediates plasticity of scirrhous gastric carcinoma motility. Clin Exp Metastasis 28:627-636

Mertsch S, Thanos S (2014) Opposing signaling of ROCK1 and ROCK2 determines the switching of substrate specificity and the mode of migration of glioblastoma cells. Mol Neurobiol 49:900-915

Mikuriya Y, Tashiro H, Kuroda S et al (2015) Fatty liver creates a pro-metastatic microenvironment for hepatocellular carcinoma through activation of hepatic stellate cells. Int J Cancer 136:E3E13
Mishra RK, Alokam R, Singhal SM et al (2014) Design of novel rho kinase inhibitors using energy based pharmacophore modeling, shape-based screening, in silico virtual screening, and biological evaluation. J Chem Inf Model 54:2876-2886

Montalvo J, Spencer C, Hackathorn A et al (2013) ROCK1 and 2 perform overlapping and unique roles in angiogenesis and angiosarcoma tumor progression. Curr Mol Med 13:205-219

Morgan-Fisher M, Wewer UM, Yoneda A (2013) Regulation of ROCK activity in cancer. J Histochem Cytochem 61:185-198

Nakabayashi H, Shimizu K (2011) HA1077, a Rho kinase inhibitor, suppresses glioma-induced angiogenesis by targeting the RhoROCK and the mitogen-activated protein kinase kinase/extracellular signal-regulated kinase (MEK/ERK) signal pathways. Cancer Sci 102:393-399

Nakagawa O, Fujisawa K, Ishizaki T et al (1996) ROCK-I and ROCK-II, two isoforms of Rho-associated coiled-coil forming protein serine/threonine kinase in mice. FEBS Lett 392:189-193

Nakashima M, Adachi S, Yasuda I et al (2010) Rho-kinase regulates negatively the epidermal growth factor-stimulated colon cancer cell proliferation. Int J Oncol 36:585-592

Nakashima M, Adachi S, Yasuda I et al (2011) Inhibition of Rhoassociated coiled-coil containing protein kinase enhances the activation of epidermal growth factor receptor in pancreatic cancer cells. Mol Cancer 10:79

Newell-Litwa KA, Badoual M, Asmussen H et al (2015) ROCK1 and 2 differentially regulate actomyosin organization to drive cell and synaptic polarity. J Cell Biol 210:225-242

Nishioka T, Shohag MH, Amano M, Kaibuchi K (2015) Developing novel methods to search for substrates of protein kinases such as Rho-kinase. Biochim Biophys Acta 1854(10 Pt B):1663-1666

Nishioka T, Nakayama M, Amano M et al (2012) Proteomic screening for Rho-kinase substrates by combining kinase and phosphatase inhibitors with 14-3-3zeta affinity chromatography. Cell Struct Funct 37:39-48

Ogata S, Morishige K, Sawada K et al (2009) Fasudil inhibits lysophosphatidic acid-induced invasiveness of human ovarian cancer cells. Int J Gynecol Cancer 19:1473-1480

Oh KS, Mun J, Cho JE et al (2013a) Discovery of novel scaffolds for Rho kinase 2 inhibitor through TRFRET-based high throughput screening assay. Comb Chem High Throughput Screen 16:37-46

Oh KS, Oh BK, Park CH et al (2013b) Cardiovascular effects of a novel selective Rho kinase inhibitor, 2-(1H-indazole-5-yl)amino4-methoxy-6-piperazino triazine (DW1865). Eur J Pharmacol 702:218-226

Ohashi K, Nagata K, Maekawa M et al (2000) Rho-associated kinase ROCK activates LIM-kinase 1 by phosphorylation at threonine 508 within the activation loop. J Biol Chem 275:3577-3582

Ohata H, Ishiguro T, Aihara Y et al (2012) Induction of the stem-like cell regulator CD44 by Rho kinase inhibition contributes to the maintenance of colon cancer-initiating cells. Cancer Res 72:5101-5110

Ohta T, Takahashi T, Shibuya T et al (2012) Inhibition of the Rho/ ROCK pathway enhances the efficacy of cisplatin through the blockage of hypoxia-inducible factor-1alpha in human ovarian cancer cells. Cancer Biol Ther 13:25-33

Oku Y, Tareyanagi C, Takaya S et al (2014) Multimodal effects of small molecule ROCK and LIMK inhibitors on mitosis, and their implication as anti-leukemia agents. PLoS One 9:e92402

Ongusaha PP, Kim HG, Boswell SA et al (2006) RhoE is a prosurvival p53 target gene that inhibits ROCK I-mediated apoptosis in response to genotoxic stress. Curr Biol 16:2466-2472

Palechor-Ceron N, Suprynowicz FA, Upadhyay G et al (2013) Radiation induces diffusible feeder cell factor(s) that cooperate with ROCK inhibitor to conditionally reprogram and immortalize epithelial cells. Am J Pathol 183:1862-1870 
Pankey EA, Byun RJ, Smith WB et al (2012) The Rho kinase inhibitor azaindole-1 has long-acting vasodilator activity in the pulmonary vascular bed of the intact chest rat. Can J Physiol Pharmacol 90:825-835

Pankova D, Jobe N, Kratochvilova M et al (2012) NG2-mediated Rho activation promotes amoeboid invasiveness of cancer cells. Eur $\mathrm{J}$ Cell Biol 91:969-977

Patel RA, Forinash KD, Pireddu R et al (2012) RKI-1447 is a potent inhibitor of the Rho-associated ROCK kinases with anti-invasive and antitumor activities in breast cancer. Cancer Res 72:50255034

Patel RA, Liu Y, Wang B et al (2014) Identification of novel ROCK inhibitors with anti-migratory and anti-invasive activities. Oncogene 33:550-555

Pearce LR, Komander D, Alessi DR (2010) The nuts and bolts of AGC protein kinases. Nat Rev Mol Cell Biol 11:9-22

Peng J, Zhang G, Wang Q et al (2012) ROCK cooperated with ET-1 to induce epithelial to mesenchymal transition through SLUG in human ovarian cancer cells. Biosci Biotechnol Biochem 76:42-47

Peng F, Jiang J, Yu Y et al (2013) Direct targeting of SUZ12/ROCK2 by $\mathrm{miR}-200 \mathrm{~b} / \mathrm{c}$ inhibits cholangiocarcinoma tumourigenesis and metastasis. Br J Cancer 109:3092-3104

Pinner S, Sahai E (2008) PDK1 regulates cancer cell motility by antagonising inhibition of ROCK1 by RhoE. Nat Cell Biol 10:127-137

Pireddu R, Forinash KD, Sun NN et al (2012) Pyridylthiazole-based ureas as inhibitors of Rho associated protein kinases (ROCK1 and 2). Medchemcomm 3:699-709

Prudnikova TY, Rawat SJ, Chernoff J (2015) Molecular pathways: targeting the kinase effectors of RHO-family GTPases. Clin Cancer Res 21:24-29

Rana MK, Worthylake RA (2012) Novel mechanism for negatively regulating Rho-kinase (ROCK) signaling through Coronin1B protein in neuregulin 1 (NRG-1)-induced tumor cell motility. J Biol Chem 287:21836-21845

Rath N, Olson MF (2012) Rho-associated kinases in tumorigenesis: re-considering ROCK inhibition for cancer therapy. EMBO Rep 13:900-908

Riento K, Guasch RM, Garg R et al (2003) RhoE binds to ROCK I and inhibits downstream signaling. Mol Cell Biol 23:4219-4229

Rikitake Y, Oyama N, Wang CY et al (2005) Decreased perivascular fibrosis but not cardiac hypertrophy in ROCK1 \pm haploinsufficient mice. Circulation 112:2959-2965

Rochelle T, Daubon T, Van Troys M et al (2013) p210bcr-abl induces amoeboid motility by recruiting ADF/destrin through RhoA/ ROCK1. FASEB J 27:123-134

Routhier A, Astuccio M, Lahey D et al (2010) Pharmacological inhibition of Rho-kinase signaling with Y-27632 blocks melanoma tumor growth. Oncol Rep 23:861-867

Sadok A, Marshall CJ (2014) Rho GTPases: masters of cell migration. Small GTPases 5:e29710

Sadok A, McCarthy A, Caldwell J et al (2015) Rho kinase inhibitors block melanoma cell migration and inhibit metastasis. Cancer Res 75:2272-2284

Saenz FR, Ory V, AlOtaiby M et al (2014) Conditionally reprogrammed normal and transformed mouse mammary epithelial cells display a progenitor-cell-like phenotype. PLoS One 9:e97666

Saito K, Ozawa Y, Hibino K et al (2012) FilGAP, a Rho/Rhoassociated protein kinase-regulated GTPase-activating protein for Rac, controls tumor cell migration. Mol Biol Cell 23:4739-4750

Samuel MS, Lopez JI, McGhee EJ et al (2011) Actomyosin-mediated cellular tension drives increased tissue stiffness and beta-catenin activation to induce epidermal hyperplasia and tumor growth. Cancer Cell 19:776-791
Sapet C, Simoncini S, Loriod B et al (2006) Thrombin-induced endothelial microparticle generation: identification of a novel pathway involving ROCK-II activation by caspase-2. Blood 108:1868-1876

Sari I, Berberoglu B, Ozkara E et al (2013) Role of rho-kinase gene polymorphisms and protein expressions in colorectal cancer development. Pathobiology 80:138-145

Sawada N, Liao JK (2014) Rho/Rho-associated coiled-coil forming kinase pathway as therapeutic targets for statins in atherosclerosis. Antioxid Redox Signal 20:1251-1267

Schackmann RC, van Amersfoort M, Haarhuis JH et al (2011) Cytosolic p120-catenin regulates growth of metastatic lobular carcinoma through Rock1-mediated anoikis resistance. J Clin Invest 121:3176-3188

Schmidt LJ, Duncan K, Yadav N et al (2012) RhoA as a mediator of clinically relevant androgen action in prostate cancer cells. Mol Endocrinol 26:716-735

Schofield AV, Bernard O (2013) Rho-associated coiled-coil kinase (ROCK) signaling and disease. Crit Rev Biochem Mol Biol 48:301-316

Sebbagh M, Renvoize C, Hamelin J et al (2001) Caspase-3-mediated cleavage of ROCK I induces MLC phosphorylation and apoptotic membrane blebbing. Nat Cell Biol 3:346-352

Sebbagh M, Hamelin J, Bertoglio J et al (2005) Direct cleavage of ROCK II by granzyme B induces target cell membrane blebbing in a caspase-independent manner. J Exp Med 201:465-471

Shen M, Yu H, Li Y et al (2013) Discovery of Rho-kinase inhibitors by docking-based virtual screening. Mol Biosyst 9:1511-1521

Shi J, Wei L (2007) Rho kinase in the regulation of cell death and survival. Arch Immunol Ther Exp 55:61-75

Shi J, Wei L (2013) Rho kinases in cardiovascular physiology and pathophysiology: the effect of fasudil. J Cardiovasc Pharmacol 62:341-354

Shi J, Zhang L, Wei L (2011) Rho-kinase in development and heart failure: insights from genetic models. Pediatr Cardiol 32:297-304

Shi J, Surma M, Zhang L et al (2013a) Dissecting the roles of ROCK isoforms in stress-induced cell detachment. Cell Cycle 12:1492-1500

Shi J, Wu X, Surma M et al (2013b) Distinct roles for ROCK1 and ROCK2 in the regulation of cell detachment. Cell Death Dis 4:e483

Shibuya M, Suzuki Y, Sugita K et al (1992) Effect of AT877 on cerebral vasospasm after aneurysmal subarachnoid hemorrhage. Results of a prospective placebo-controlled double-blind trial. J Neurosurg 76:571-577

Shimizu Y, Thumkeo D, Keel J et al (2005) ROCK-I regulates closure of the eyelids and ventral body wall by inducing assembly of actomyosin bundles. J Cell Biol 168:941-953

Shimizu T, Fukumoto Y, Tanaka S et al (2013) Crucial role of ROCK2 in vascular smooth muscle cells for hypoxia-induced pulmonary hypertension in mice. Arterioscler Thromb Vasc Biol 33:2780-2791

Shin JY, Kim YI, Cho SJ et al (2014) MicroRNA 135a suppresses lymph node metastasis through down-regulation of ROCK1 in early gastric cancer. PLoS One 9:e85205

Shirao S, Kashiwagi S, Sato M et al (2002) Sphingosylphosphorylcholine is a novel messenger for Rho-kinase-mediated $\mathrm{Ca}^{2+}$ sensitization in the bovine cerebral artery: unimportant role for protein kinase C. Circ Res 91:112-119

Soliman H, Nyamandi V, Garcia-Patino M et al (2015) Partial deletion of ROCK2 protects mice from high-fat diet-induced cardiac insulin resistance and contractile dysfunction. American journal of physiology. Am J Physiol Heart Circ Physiol 309:H70-H81

Spencer C, Montalvo J, McLaughlin SR et al (2011) Small molecule inhibition of cytoskeletal dynamics in melanoma tumors results 
in altered transcriptional expression patterns of key genes involved in tumor initiation and progression. Cancer Genomics Proteomics 8:77-85

Stiles JM, Kurisetty V, Mitchell DC et al (2013) Rho kinase proteins regulate global miRNA expression in endothelial cells. Cancer Genomics Proteomics 10:251-263

Street CA, Bryan BA (2011) Rho kinase proteins-pleiotropic modulators of cell survival and apoptosis. Anticancer Res 31:3645-3657

Street CA, Routhier AA, Spencer C et al (2010) Pharmacological inhibition of Rho-kinase (ROCK) signaling enhances cisplatin resistance in neuroblastoma cells. Int J Oncol 37:1297-1305

Sumi T, Matsumoto K, Nakamura T (2001) Specific activation of LIM kinase 2 via phosphorylation of threonine 505 by ROCK, a Rho-dependent protein kinase. J Biol Chem 276:670-676

Suprynowicz FA, Upadhyay G, Krawczyk E et al (2012) Conditionally reprogrammed cells represent a stem-like state of adult epithelial cells. Proc Natl Acad Sci USA 109:20035-20040

Surma M, Handy C, Chang J et al (2014) ROCK1 deficiency enhances protective effects of antioxidants against apoptosis and cell detachment. PLoS One 9:e90758

Takeba Y, Matsumoto N, Watanabe M et al (2012) The Rho kinase inhibitor fasudil is involved in p53-mediated apoptosis in human hepatocellular carcinoma cells. Cancer Chemother Pharmacol 69:1545-1555

Tang F, Zou F, Peng Z et al (2011) N, N'-dinitrosopiperazinemediated ezrin protein phosphorylation via activation of Rho kinase and protein kinase $\mathrm{C}$ is involved in metastasis of nasopharyngeal carcinoma $6-10 \mathrm{~B}$ cells. J Biol Chem 286:36956-36967

Tanihara H, Inoue T, Yamamoto T et al (2013a) Phase 1 clinical trials of a selective Rho kinase inhibitor, K-115. JAMA Ophthalmol 131:1288-1295

Tanihara H, Inoue T, Yamamoto T et al (2013b) Phase 2 randomized clinical study of a Rho kinase inhibitor, K-115, in primary openangle glaucoma and ocular hypertension. Am J Ophthalmol 156:731-736

Thumkeo D, Keel J, Ishizaki T et al (2003) Targeted disruption of the mouse rho-associated kinase 2 gene results in intrauterine growth retardation and fetal death. Mol Cell Biol 23:5043-5055

Tilson SG, Haley EM, Triantafillu UL et al (2015) ROCK inhibition facilitates in vitro expansion of glioblastoma stem-like cells. PLoS One 10:e0132823

Timpson P, McGhee EJ, Morton JP et al (2011) Spatial regulation of RhoA activity during pancreatic cancer cell invasion driven by mutant p53. Cancer Res 71:747-757

Tsai CC, Liu HF, Hsu KC et al (2011) 7-Chloro-6-piperidin-1-ylquinoline-5,8-dione (PT-262), a novel ROCK inhibitor blocks cytoskeleton function and cell migration. Biochem Pharmacol 81:856-865

Uehata M, Ishizaki T, Satoh $\mathrm{H}$ et al (1997) Calcium sensitization of smooth muscle mediated by a Rho-associated protein kinase in hypertension. Nature 389:990-994

Ueno K, Hirata H, Shahryari V et al (2011) Tumour suppressor microRNA-584 directly targets oncogene Rock-1 and decreases invasion ability in human clear cell renal cell carcinoma. Br J Cancer 104:308-315

Upadhyaya M, Spurlock G, Thomas L et al (2012) Microarray-based copy number analysis of neurofibromatosis type-1 (NF1)-associated malignant peripheral nerve sheath tumors reveals a role for Rho-GTPase pathway genes in NF1 tumorigenesis. Hum Mutat 33:763-776

Van de Velde S, Van Bergen T et al (2014) AMA0076, a novel, locally acting Rho kinase inhibitor, potently lowers intraocular pressure in New Zealand white rabbits with minimal hyperemia. Invest Ophthalmol Vis Sci 55:1006-1016
Vega FM, Fruhwirth G, Ng T et al (2011) RhoA and RhoC have distinct roles in migration and invasion by acting through different targets. J Cell Biol 193:655-665

Vigil D, Kim TY, Plachco A et al (2012) ROCK1 and ROCK2 are required for non-small cell lung cancer anchorage-independent growth and invasion. Cancer Res 72:5338-5347

Vishnubhotla R, Bharadwaj S, Sun S et al (2012) Treatment with Y-27632, a ROCK inhibitor, increases the proinvasive nature of SW620 cells on 3D collagen type 1 matrix. Int J Cell Biol 2012:259142

Vogel CJ, Smit MA, Maddalo G et al (2015) Cooperative induction of apoptosis in NRAS mutant melanoma by inhibition of MEK and ROCK. Pigment Cell Melanoma Res 28:307-317

Voorneveld PW, Kodach LL, Jacobs RJ et al (2014) Loss of SMAD4 alters BMP signaling to promote colorectal cancer cell metastasis via activation of Rho and ROCK. Gastroenterology 147:196.e113-208.e113

Wan X, Cheng Q, Peng R et al (2014) ROCK1, a novel target of miR145, promotes glioma cell invasion. Mol Med Rep 9:1877-1882

Wang HF, Takenaka K, Nakanishi A et al (2011) BRCA2 and nucleophosmin coregulate centrosome amplification and form a complex with the Rho effector kinase ROCK2. Cancer Res 71:68-77

Wang J, Liu XH, Yang ZJ et al (2014) The effect of ROCK-1 activity change on the adhesive and invasive ability of Y79 retinoblastoma cells. BMC Cancer 14:89

Wang RF, Williamson JE, Kopczynski C et al (2015) Effect of $0.04 \%$ AR-13324, a ROCK, and norepinephrine transporter inhibitor, on aqueous humor dynamics in normotensive monkey eyes. J Glaucoma 24:51-54

Watanabe K, Ueno M, Kamiya D et al (2007) A ROCK inhibitor permits survival of dissociated human embryonic stem cells. Nat Biotechnol 25:681-686

Watzlawick R, Sena ES, Dirnagl U et al (2014) Effect and reporting bias of RhoA/ROCK-blockade intervention on locomotor recovery after spinal cord injury: a systematic review and metaanalysis. JAMA Neurol 71:91-99

Wei L, Surma M, Gough G et al (2015) Dissecting the mechanisms of doxorubicin and oxidative stress-induced cytotoxicity: the involvement of actin cytoskeleton and ROCK1. PLoS One 10:e 0131763

Wen W, Liu W, Yan J et al (2008) Structure basis and unconventional lipid membrane binding properties of the $\mathrm{PH}-\mathrm{C} 1$ tandem of rho kinases. J Biol Chem 283:26263-26273

Wen X, Huang A, Liu Z et al (2014) Downregulation of ROCK2 through nanocomplex sensitizes the cytotoxic effect of temozolomide in U251 glioma cells. PLoS One 9:e92050

Wermke M, Camgoz A, Paszkowski-Rogacz M et al (2015) RNAi profiling of primary human AML cells identifies ROCK1 as a therapeutic target and nominates fasudil as an antileukemic drug. Blood 125:3760-3768

Williams RD, Novack GD, van Haarlem T et al (2011) Ocular hypotensive effect of the Rho kinase inhibitor AR-12286 in patients with glaucoma and ocular hypertension. Am J Ophthalmol 152(834-841):e831

Wong CC, Wong CM, Tung EK et al (2009) Rho-kinase 2 is frequently overexpressed in hepatocellular carcinoma and involved in tumor invasion. Hepatology 49:1583-1594

Wong CC, Wong CM, Tung EK et al (2011) The microRNA miR-139 suppresses metastasis and progression of hepatocellular carcinoma by down-regulating Rho-kinase 2. Gastroenterology 140:322-331

Wong SY, Ulrich TA, Deleyrolle LP et al (2015) Constitutive activation of myosin-dependent contractility sensitizes glioma tumor-initiating cells to mechanical inputs and reduces tissue invasion. Cancer Res 75:1113-1122

Xu Z, Zheng X, Yang L et al (2015) Chemokine receptor 7 promotes tumor migration and invasiveness via the RhoA/ROCK pathway 
in metastatic squamous cell carcinoma of the head and neck. Oncol Rep 33:849-855

Yamaguchi H, Kasa M, Amano M et al (2006) Molecular mechanism for the regulation of rho-kinase by dimerization and its inhibition by fasudil. Structure 14:589-600

Yamamoto K, Maruyama K, Himori N et al (2014) The novel Rho kinase (ROCK) inhibitor K-115: a new candidate drug for neuroprotective treatment in glaucoma. Invest Ophthalmol Vis Sci 55:7126-7136

Yang S, Kim HM (2012) The RhoA-ROCK-PTEN pathway as a molecular switch for anchorage dependent cell behavior. Biomaterials 33:2902-2915

Yang S, Kim HM (2014) ROCK inhibition activates MCF-7 cells. PLoS One 9:e88489

Yang X, Zhang Y, Wang S et al (2010) Effect of fasudil on growth, adhesion, invasion, and migration of 95D lung carcinoma cells in vitro. Can J Physiol Pharmacol 88:874-879

Yang X, Di J, Zhang Y et al (2012) The Rho-kinase inhibitor inhibits proliferation and metastasis of small cell lung cancer. Biomed Pharmacother 66:221-227

Yin Z, Sun J (2014) Curcumin induces human SKOV3 cell apoptosis via the activation of Rho-kinase. Eur $\mathrm{J}$ Gynaecol Oncol 35:433-437

Yoneda A, Morgan-Fisher M, Wait R et al (2012) A collapsin response mediator protein 2 isoform controls myosin II-mediated cell migration and matrix assembly by trapping ROCK II. Mol Cell Biol 32:1788-1804

Yoshikawa T, Wu J, Otsuka M et al (2015) ROCK inhibition enhances microRNA function by promoting deadenylation of targeted mRNAs via increasing PAIP2 expression. Nucleic Acids Res 43:7577-7589

Yugawa T, Nishino K, Ohno S et al (2013) Noncanonical NOTCH signaling limits self-renewal of human epithelial and induced pluripotent stem cells through ROCK activation. Mol Cell Biol 33:4434-4447

Zanin-Zhorov A, Weiss JM, Nyuydzefe MS et al (2014) Selective oral ROCK2 inhibitor down-regulates IL-21 and IL-17 secretion in human T cells via STAT3-dependent mechanism. Proc Natl Acad Sci USA 111:16814-16819

Zhang YM, Bo J, Taffet GE et al (2006) Targeted deletion of ROCK1 protects the heart against pressure overload by inhibiting reactive fibrosis. FASEB J 20:916-925

Zhang L, Valdez JM, Zhang B et al (2011) ROCK inhibitor Y-27632 suppresses dissociation-induced apoptosis of murine prostate stem/progenitor cells and increases their cloning efficiency. PLoS One 6:e18271

Zhang Z, Ren JH, Li ZY et al (2012) Fasudil inhibits lung carcinomaconditioned endothelial cell viability and migration. Oncol Rep 27:1561-1566

Zhang C, Zhang S, Zhang Z et al (2014) ROCK has a crucial role in regulating prostate tumor growth through interaction with c-Myc. Oncogene 33:5582-5591

Zhang P, Lu Y, Liu XY et al (2015) Knockdown of Rho-associated protein kinase 1 suppresses proliferation and invasion of glioma cells. Tumour Biol 36:421-428

Zheng B, Liang L, Wang C et al (2011) MicroRNA-148a suppresses tumor cell invasion and metastasis by downregulating ROCK1 in gastric cancer. Clin Cancer Res 17:7574-7583

Zheng F, Liao YJ, Cai MY et al (2012) The putative tumour suppressor microRNA-124 modulates hepatocellular carcinoma cell aggressiveness by repressing ROCK2 and EZH2. Gut 61:278-289

Zheng F, Liao YJ, Cai MY et al (2015) Systemic delivery of microRNA-101 potently inhibits hepatocellular carcinoma in vivo by repressing multiple targets. PLoS Genet 11:e1004873

Zhou X, Wei M, Wang W (2013) MicroRNA-340 suppresses osteosarcoma tumor growth and metastasis by directly targeting ROCK1. Biochem Biophys Res Commun 437:653-658

Zhu F, Zhang Z, Wu G et al (2011) Rho kinase inhibitor fasudil suppresses migration and invasion though down-regulating the expression of VEGF in lung cancer cell line A549. Med Oncol 28:565-571 